\title{
Moments-based spillovers across gold and oil markets
}

Article

Accepted Version

Creative Commons: Attribution-Noncommercial-No Derivative Works 4.0

Bonato, M., Gupta, R., Lau, C. K. M. and Wang, S. (2020) Moments-based spillovers across gold and oil markets. Energy Economics, 89. 104799. ISSN 0140-9883 doi: https://doi.org/10.1016/j.eneco.2020.104799 Available at https://centaur.reading.ac.uk/90772/

It is advisable to refer to the publisher's version if you intend to cite from the work. See Guidance on citing.

To link to this article DOI: http://dx.doi.org/10.1016/j.eneco.2020.104799

Publisher: Elsevier

All outputs in CentAUR are protected by Intellectual Property Rights law, including copyright law. Copyright and IPR is retained by the creators or other copyright holders. Terms and conditions for use of this material are defined in the End User Agreement.

\section{www.reading.ac.uk/centaur}

\section{CentAUR}

Central Archive at the University of Reading

Reading's research outputs online 


\title{
Moments-Based Spillovers across Gold and Oil Markets ${ }^{\dagger}$
}

\begin{abstract}
In this paper, we use intraday futures market data on gold and oil to compute returns, realized volatility, volatility jumps, realized skewness and realized kurtosis. Using these daily metrics associated with two markets over the period of December 2, 1997 to May 26, 2017, we conduct linear, nonparametric, and time-varying (rolling) tests of causality, with the latter two approaches motivated due to the existence of nonlinearity and structural breaks. While, there is hardly any evidence of spillovers between the returns of these two markets, strong evidence of bidirectional causality is detected for realized volatility, which seems to be resulting from volatility jumps. Evidence of spillovers are also detected for the crash risk variables, i.e., realized skewness, and for realized kurtosis as well, with the effect on the latter being relatively stronger. Based on a moments-based test of causality, evidence of co-volatility is deduced, whereby we find that extreme positive and negative returns of gold and oil tend to drive the volatilities in these markets. In our robustness check, we identify a causal chain in the realized volatility from oil to gold via the financial stress. Our results have important implications for not only investors, but also policymakers.
\end{abstract}

JEL Codes: C32, Q02

Keywords: Gold and Oil Markets; Linear, Nonparametric and Time-Varying Causality Tests; Moments-Based Spillovers

\footnotetext{
${ }^{\dagger}$ Acknowledgement: we would like to thank two anonymous referees for many helpful comments. However, any remaining errors are solely ours.
} 


\section{Introduction}

The severity of the recent global financial crisis highlighted the risks associated with portfolios containing only conventional financial market assets (Balcilar et al., 2017; Lau et al., 2017; Muteba Mwamba et al., 2017; Bilgin et al., 2018). This in turn has triggered an interest in considering investment opportunities in the energy (specifically oil) market (Degiannakis and Filis, 2017; Bahloul et al., 2018; Cunado et al., 2019), since the recent financialization of the commodity (including oil) market (Tang and Xiong, 2012; Silvennoinen and Thorp, 2013;Bonato and Taschini, 2016;Bonato, 2019) has resulted in an increased participation of hedge funds, pension funds, and insurance companies in the market, with investment in oil now being considered as a profitable alternative instrument in the portfolio decisions of financial institutions (Akram, 2009; Fattouh et al., 2013; Büyükşahin and Robe, 2014; Antonakakis et al., 2018). Not surprisingly, the market-size of oil stands at $\$ 1.7$ trillion per year at current spot prices, with 34 billion barrels produced each year and over 1.7 trillion barrels of crude oil in remaining reserves (U.S. Energy Information Administration (EIA); BP Statistical Review of World Energy).

At the same time, with gold being the most recognized "safe haven” (Bilgin et al., 2018; Bouoiyour et al., 2018) ${ }^{1}$, recent studies have analyzed returns and volatility spillovers across the gold and oil markets ( Coronado et al., 2018; Balcilar et al., 2019; Asasi et al., forthcoming; Tiwari et al., forthcoming)². Note that, gold is the world's largest metal market by dollar value, which in turn is $\$ 170$ billion per year at current spot prices, with a production of over 3200 tonnes per annum and 54,000 tonnes of economically extractable gold reserves remaining (World Gold Council). The emphasis on returns and volatility connectedness between oil and gold is understandably due to the fact that such causal

\footnotetext{
${ }^{1}$ See also the large literature in this regard in the works of Baur and Lucey (2010), Baur and McDermott (2010), Reboredo (2013a), Agyei-Ampomah et al., (2014), Gürgün and Ünalmis (2014), Beckmann et al., (2015, 2019), and Balcilar et al., (2016).

${ }^{2}$ Other relevant studies in this regard involves the work of Ewing and Malik( 2013), Mensi et al., (2013), Reboredo (2013b), Bampinas and Panagiotidis, 2015; and Yaya et al., (2016)..
} 
relationships is of paramount importance to international investors and portfolio managers in devising optimal portfolio and dynamic hedging strategies (Chang et al., 2018a).

In this regard, it is also important to point out that financial market participants care not only about the nature of volatility, but also its level, with traders making the distinction between "good" and "bad" volatility (Giot et al., 2010; Caporin et al., 2016). Good volatility is directional, persistent, and relatively easy to predict, while bad volatility is jumpy and comparatively difficult to foresee. Therefore, good volatility is generally associated with the continuous and persistent part of volatility, while bad volatility captures the discontinuous and jump component of volatility, with jumps shown to account for a significant percentage of variation in total return volatility of assets in general (Andersen et al., 2007; Dunham and Friesen, 2007; Bollerslev et al., 2009; Corsi et al., 2010), and also for gold and oil volatility (Balcilar et al., 2017; Demirer et al., 2019; Gkillas et al., forthcoming). Given this, studies like Amaya et al., (2015) and Nolte and Xu (2015) point out that investment strategies using jump risks, as well as skewness and kurtosis are shown to reveal additional information and deliver incremental economic benefits over strategies using total volatility alone. Note that, skewness account for the asymmetry in the returns process, while kurtosis captures the extremes of the same, with the former also considered as capturing crash-risks in asset markets (Kräussl et al., 2016; Greenwood-Nimmo et al., 2016; Ben Nasr et al., 2019).

In light of the above-mentioned importance of higher-moments of assets in improving portfolio performances, we, for the first time, analyze the causal relationship between not only returns and overall variance of gold and oil markets, but also volatility jumps, skewness and kurtosis. With the availability of high-frequency, i.e., intraday data, research on modelling higher moments has taken new directions, and hence, we use 5-minute futures market data on gold and oil returns, which are then used to compute realized volatility, jumps, realized skewness and kurtosis, over the daily period of December 2, 1997 to May 26, 2017. We then analyze the causal relationship between these metrics for gold and oil markets, using linear, nonparametric and time-varying approaches, with the latter two methods providing robust inferences in the presence of nonlinearity and structural breaks between the variables of concern, which 
we show to exist based on statistical tests. In addition, we also rely on a moments-based test of causality, which allows us to test for spillovers of returns, variances and quantiles.

The remainder of the paper is organized as follows: Section 2 outlines the various methodologies used, while Section 3 presents the intraday data and the details associated with the calculation of realized volatility, jumps, realized skewness and kurtosis. Then, Section 4 discusses the empirical results, with Section 5 presents the robustness check. Section 6 provides concluding remarks and implications.

\section{Methodologies}

We carried out four forms of Granger causality analysis to fully reveal the causal relationships between gold and oil with various considerations. We discuss the merits and drawbacks of different causality tests in this section, and technical details of methodologies are provided in Appendix A. To be specific, four forms of casualty analysis include: $i$ ) linear causality analysis, which is the basic and standard Granger causality analysis; ii) nonlinear causality analysis developed by Diks and Panchenko (2006); iii) trivariate causality analysis and the rolling-window scheme, developed by Hill (2007); iv) causality in moments developed by Chen (2016). More importantly, our causality analysis is not only at the first moment but also at higher moments, including volatility, jump, skewness, kurtosis, and quantiles. For volatility, skewness, and kurtosis, we are using the realized versions calculated by the high-frequency intraday data.

The linear causality analysis serves as the benchmark of this study. Given two scalar stationary time series $\left\{X_{t}, Y_{t}, t \geq 1\right\}$, the linear causality analysis can be easily tested in the framework of bivariate VAR with $p$ lags.

$$
\begin{aligned}
& Y_{t}=\alpha_{1}+\sum_{i=1}^{p} \beta_{1 i} Y_{t-i}+\sum_{i=1}^{p} \gamma_{1 i} X_{t-i}+\varepsilon_{1 t} \\
& X_{t}=\alpha_{2}+\sum_{i=1}^{p} \beta_{2 i} Y_{t-i}+\sum_{i=1}^{p} \gamma_{2 i} X_{t-i}+\varepsilon_{2 t}
\end{aligned}
$$


With all other information as the same, $Y_{t}$ does not Granger cause $X_{t}$ if the lags of $Y_{t}$ does not bring additional contribution to the forecasting performance of $X_{t}$, (Granger, 1969). Thus, the null hypothesis that $Y_{t}$ does not Granger cause $X_{t}$, denoted as $Y_{t} \nrightarrow X_{t}$, can be formulated by testing whether all coefficients of lags of $Y_{t}$ are jointly equal to zero in the equation that $X_{t}$ is the dependent variable. The direct way to perform the Granger causality in such a setting is to use a standard $F$-test on the following restrictions

$$
\beta_{21}=\beta_{22}=\cdots=\beta_{2 p}
$$

If the $F$-test is rejected, then there is evidence to support that that $Y_{t}$ Granger cause $X_{t}$. The optimal lag length $p$ of VAR is typically selected by information criteria.

The linear causality analysis based on Equation (1) is straightforward, but it sometimes oversimplifies the actual relationship between economic variables. A vast number of empirical studies found evidence that economic relationships could be nonlinear, especially involving high-frequency data (Kumar, 2017), as we show by the Brock et al., (1996, BDS) test for our dataset in Section 4.2. Hiemstra and Jones (1994) proposed a nonparametric test for both linear and nonlinear Granger causality by using conditional independence. However, the size of their test (rejection rate under the null hypothesis) is argued to be inflated and increases with the sample size (Diks and Panchenko, 2005). Diks and Panchenko (2006) further developed a revised nonparametric test for nonlinear Granger causality with reasonable control on the size of the test.

Based on Wald tests for the null hypothesis of joint zero parameter restrictions, Hill (2007) developed a sequential multiple-horizon non-causality test procedure for trivariate VAR processes (with one auxiliary variable) in both whole sample and rolling-window scheme. ${ }^{3}$ Comparing with the linear and nonlinear causality analysis, there are two merits associated with the framework of Hill (2007) causality test. The first merit is due to the trivariate framework, which is useful to distinguish between the direct causality and the causal chain. With an extra auxiliary variable, the causality relationship can be existed

\footnotetext{
${ }^{3}$ The rolling-window scheme in Hill (2007) can be used for both bivariate and trivariate framework. In Hill (2007), he studied the rolling-window causality from money to income with one auxiliary variable, i.e. the trivariate framework. Bampinas and Panagiotidis (2015) employed the bivariate setting of Hill's (2007) test to investigate the rolling-window causality between oil and gold.
} 
in two channels: 1) $Y_{t}$ directly causes $X_{t}$, representing a direct causality; and 2) $Y_{t}$ causes the auxiliary variable $U_{t}$ and $U_{t}$ further causes $X_{t}$, which is characterized as the causal chain. In our Section 5 , we employ the trivariate version of Hill (2007) test procedure with one auxiliary variable in order to check the robustness of the causality between gold and oil. The second merit of Hill (2007) is with regards to the rolling-window scheme. During a long sample periods, the economic variables are typically subject to structural breaks, which may affect the causal relationships (Balcilar, et al., 2010). Our dataset lasts for about two decades, and it is highly likely that the causal relationships we are investigating are subject to structural breaks. With little loss in generality, we use a bivariate version (i.e. without the auxiliary variable) of Hill (2007) test at horizon one ${ }^{4}$ in the rolling-window scheme in our Section 4.3.

Given the possibility of Granger causality in the cross quantiles and moments, we expand our analysis by using return series to perform the casualty-in-moments test suggested by Chen (2016). Unlike the existing causality tests, the major novelty of Chen (2016) test is due to its extension in studying the causality in mean, variance, quantiles and more importantly, their cross-causality (a.k.a. crosscorrelation in Chen (2016)). For instance, it possible that the left tail in a return distribution could cause the right tail in another return distribution. The question related to the cross-causality cannot be revealed by using the realized moments in other causality test frameworks, and thus Chen (2016) can provide additional information on the comprehensive causality analysis between gold and return, which are reported in our Section 4.4 .

\section{Data and Higher-Moment Statistics}

\section{1. $\quad$ The Dataset}

We use intraday data on gold and West Texas Intermediate (WTI) oil futures that are traded at NYMEX over a 24 hour trading day (pit and electronic), to construct daily measures of returns ( $r$ ), standard realized volatility $(R V)$, volatility jumps $(R J)$, and realized skewness $(R S K)$ and realized kurtosis $(R K U)$. The futures intraday price data, in continuous format, are obtained from two sources,

\footnotetext{
${ }^{4}$ According to Theorem 2.1 in Hill (2007), causality exists at any horizon if and only if it exists at horizon one.
} 
www.disktrading.com (1997-2008) $)^{5}$ and www.kibot.com (2009-2017). Close to expiration of a contract, the position is rolled over to the next available contract, provided that activity has increased. Daily returns are computed as the end of day (New York time) price difference (close to close). In the case of intraday returns, 5-minute prices are obtained via last-tick interpolation, and 5-minute returns are then computed by taking the log-differences of these prices, which in turn are used to compute the realized moments. Our data covers the period of December 2, 1997 to May 26, 2017, i.e., giving us a total of 5762 observations. Figure B1 in the Appendix B plots the various metrics for gold and oil, while Table B1 summarizes the basic statistics for $r, R V, R J, R S K$ and $R K U$ of both gold and oil markets. As can be seen from Table B1, both gold and oil are negatively skewed and have excess kurtosis, which results in non-normal distributions as indicated by the overwhelming rejection of the null of normality under the Jarque-Bera test. Oil is also found to be more volatile than gold, though the mean returns are similar across the two markets. Further, as seen from Figure B1, $R V, R J, R S K$ and $R K U$ are non-constant, with their magnitudes evolving over time, and hence, provides an initial motivation to analyze the causal relationship between these metrics across the gold and oil markets.

An advantage of using intraday data is that we are also able to compute measures of higher moments, like realized volatility, volatility jumps, realized skewness and realized kurtosis. Below, we provide the details for the realized measures considered in the analysis.

\subsection{Realized Volatility Estimator}

The first measure we consider is the classical estimator of realized volatility, i.e. the sum of squared intraday returns (Andersen and Bollerslev, 1998), expressed as

$$
R V_{t}=\sum_{i=1}^{M} r_{t, i}^{2}
$$

where $r_{t, i}$ is the intraday $M \times 1$ return vector and $i=1, \ldots, M$ the number of intraday returns.

\footnotetext{
${ }^{5}$ www.disktrading.com is no longer accessible due to the termination of its services. The data of computed realized moments will be available online on the article webpage.
} 


\subsection{Volatility Jump Estimator}

A number of studies including Barndorff-Nielsen and Shephard (2004), Huang and Tauchen (2005), Andersen et al. (2007) have documented the presence of volatility jumps in higher frequency time series. Barndorff-Nielsen and Shephard (2004) show that realized volatility converges into permanent and discontinuous (jump) components as

$$
\lim _{M \rightarrow \infty} R V_{t}=\int_{t-1}^{t} \sigma^{2}(s) d s+\sum_{j=1}^{N_{t}} k_{t, j}^{2}
$$

where $N_{t}$ is the number of jumps within day $t$ and $k_{t, j}$ is the jump size. This specification suggests that $R V_{t}$ is a consistent estimator of the integrated variance $\int_{t-1}^{t} \sigma^{2}(s) d s$ plus the jump contribution. The asymptotic results of Barndorff-Nielsen and Shephard $(2004,2006)$ further show that

$$
\lim _{M \rightarrow \infty} B V_{t}=\int_{t-1}^{t} \sigma^{2}(s) d s
$$

where $B V_{t}$ is the realized bipolar variation defined as

$$
B V_{t}=\mu_{1}^{-1}\left(\frac{N}{M-1}\right) \sum_{i=2}^{M}\left|r_{t, i-1}\right|\left|r_{i, t}\right|=\frac{\pi}{2} \sum_{i=2}^{M}\left|r_{t, i-1}\right|\left|r_{i, t}\right|
$$

and

$$
\mu_{a}=E\left(|Z|^{a}\right), Z \sim N(0,1), a>0
$$

Having defined the continuous component of realized volatility, a consistent estimator of the pure jump contribution can then be expressed as

$$
J_{t}=R V_{t}-B V_{t}
$$

In order to test the significance of the jumps, we adopt the following formal test estimator proposed by Barndorff-Nielsen and Shephard (2006)

$$
J T_{t}=\frac{R V_{t}-B V_{t}}{\left(v_{b b}-v_{q q}\right) \frac{1}{N} Q P_{t}}
$$

where $Q P_{t}$ is the Tri-Power Quarticity defined as

$$
T P_{t}=M_{\mu_{4 / 3}^{-3}}\left(\frac{M}{M-1}\right) \sum_{i=3}^{M}\left|r_{t, i-2}\right|^{4 / 3}\left|r_{t, i}\right|^{4 / 3}
$$


which converges to

$$
T P_{t} \rightarrow \int_{t-1}^{t} \sigma^{4}(s) d s
$$

even in the presence of jumps. $v_{b b}=\left(\frac{\pi}{2}\right)^{2}+\pi-3$ and $v_{q q}=2$. Note that for each $t, J T_{t} \sim N(0,1)$ as $M \rightarrow \infty$.

As can be seen in Equation (25), the jump contribution to $R V_{t}$ is either positive or null. Therefore, in order to avoid having negative empirical contributions, we follow Zhou and Zhu (2012) and re-define the jump measure as

$$
R J_{t}=\max \left(R V_{t}-B V_{t} ; 0\right)
$$

\section{4. $\quad$ Realized Skewness and Realized Kurtosis}

We compute realized skewness, $R S K$, and realized kurtosis, $R K U$, as measures of the higher-moments of the daily returns distribution computed from intra-day returns. Like Amaya et al. (2015), we consider $R S K$ as a measure of the asymmetry of the daily returns distribution and $R K U$ as a measure that accounts for extremes. Given the intraday returns and realized volatility realized skewness (RSK) on day $t$ as

$$
R S K_{t}=\frac{\sqrt{N} \sum_{i=1}^{N}\left(r_{i, t}\right)^{3}}{R V_{t}^{3 / 2}}
$$

While, realized kurtosis (RKU) on day $t$ is given by

$$
R K U_{t}=\frac{N \sum_{i=1}^{N}\left(r_{i, t}\right)^{4}}{R V_{t}^{2}}
$$

The scaling of $R S K$ and $R K U$ by $N^{1 / 2}$ and $N$ respectively, makes sure that their magnitudes correspond to daily skewness and kurtosis.

\section{Empirical Results}

In this section, we first present the results for three causality tests (linear, Diks and Panchenko (2006), and rolling-window of bivariate version of Hill (2007)) between the returns of gold and oil, not only in the mean but also in the realized higher moments, including volatility, skewness, and kurtosis. In 
addition, the Chen (2016) test is employed to test the causality between gold and oil returns in mean, variance, quantiles, and their cross-causality.

\section{1. $\quad$ Linear Causality Analysis}

After choosing the optimal lag length for VAR by Bayesian Information Criterion (BIC), ${ }^{6}$ we perform the linear causality analysis on the returns of gold and oil and their realized higher moments. The results are shown in Table 1 . For the returns $(r)$, there is no causality between gold and oil at $5 \%$ significance level. But there is weak evidence at $10 \%$ for the causality from gold to oil. For $R V, R J$, and $R K U$, we can observe the bi-directional causality between gold and oil at the $5 \%$ significance level, but not for RSK in any direction even at the $10 \%$ level.

Table 1. Results of Linear Granger Causality

\begin{tabular}{|c|c|c|c|c|}
\hline & Causality & F-Statistic & $p$-value & Lags \\
\hline \multirow{2}{*}{$r$} & gold $\nrightarrow$ oil & 3.50 & $6.15 \%$ & \multirow{2}{*}{1} \\
\hline & oil $\nrightarrow$ gold & 0.15 & $69.99 \%$ & \\
\hline \multirow{2}{*}{$R V$} & gold $\nrightarrow$ oil & 6.36 & $0.00 \%$ & \multirow{2}{*}{13} \\
\hline & oil $\nrightarrow$ gold & 10.41 & $0.00 \%$ & \\
\hline \multirow{2}{*}{$R J$} & gold $\nrightarrow$ oil & 6.25 & $0.00 \%$ & \multirow{2}{*}{6} \\
\hline & oil $\nrightarrow$ gold & 4.31 & $0.02 \%$ & \\
\hline \multirow{2}{*}{$R S K$} & gold $\nrightarrow$ oil & 0.21 & $64.49 \%$ & \multirow{2}{*}{1} \\
\hline & oil $\nrightarrow$ gold & 0.40 & $52.80 \%$ & \\
\hline \multirow{2}{*}{$R K U$} & gold $\nrightarrow$ oil & 5.61 & $0.00 \%$ & \multirow[b]{2}{*}{6} \\
\hline & oil $\nrightarrow$ gold & 7.76 & $0.00 \%$ & \\
\hline
\end{tabular}

Note: $r$ : returns; $R V$ : realized volatility; $R J$ : jumps; $R S K$ : realized skewness, and; $R K U$ : realized kurtosis.

\subsection{Nonlinear Causality Analysis}

To motivate the use of a nonlinear causality approach, we conducted the BDS test on the residuals of the $\operatorname{VAR}(p)$ model used for the linear test of causality, with the results reported in Table B2 in the Appendix B of the paper. As can be seen, the null of i.i.d. residuals is overwhelmingly rejected in all cases, and hence, suggests the existence of uncaptured nonlinearity between returns and higher

\footnotetext{
${ }^{6}$ The maximum lag length of the VAR is set to be 15 in the standard linear causality test.
} 
moments of the gold and oil markets. This motivates the use of the nonparametric causality test of Diks and Panchenko (2006), to which we turn next.

Before carrying out the Diks and Panchenko (2006) test, it is important to select the value of bandwidth. We follow the optimal bandwidth choice in terms of the smallest mean squared error detailed in Diks and Panchenko (2006), which is derived on the basis of the ARCH process. For our dataset, the estimated ARCH parameter for return on gold is 0.2213, giving the optimal bandwidth 0.8633; and the estimated ARCH parameter for return on oil is 0.2142 , giving the optimal bandwidth 0.8815 . Therefore, we choose 0.87 which is close to the optimal bandwidth of returns of both gold and oil. Table 2 shows the $p$-values of $T_{n}$ test developed by Diks and Panchenko (2006) in both directions, for lags ranging from 1 to 10. For the returns, we can find evidence of causality from gold to oil at lags 4 and 5, but not verse visa. In terms of the $R V$, we cannot find evidence of causality in most lags. The only evidence of causality can be found from oil to gold at lag 5. Regarding RJ, RSK and RKU, we can find strong evidence of bidirectional causality between gold and oil for all lags. In summary, the nonlinear causality analysis is consistent with the linear causality analysis barring the lack of evidence of causality for $R V$ and the opposite (i.e., strong evidence of spillover) for RSK.

Table 2. $p$-Values of Nonlinear Causality Test

\begin{tabular}{|c|c|c|c|c|c|}
\hline \multicolumn{6}{|c|}{ Panel A: gold $\nrightarrow$ oil } \\
\hline Lag & $r$ & $\boldsymbol{R V}$ & $R J$ & RSK & $\boldsymbol{R K U}$ \\
\hline 1 & $38.99 \%$ & $77.58 \%$ & $0.00 \%$ & $0.00 \%$ & $0.27 \%$ \\
\hline 2 & $47.43 \%$ & $76.99 \%$ & $0.00 \%$ & $0.00 \%$ & $0.02 \%$ \\
\hline 3 & $17.76 \%$ & $39.05 \%$ & $0.00 \%$ & $0.00 \%$ & $0.05 \%$ \\
\hline 4 & $2.54 \%$ & $25.65 \%$ & $0.00 \%$ & $0.00 \%$ & $0.02 \%$ \\
\hline 5 & $2.51 \%$ & $25.96 \%$ & $0.00 \%$ & $0.04 \%$ & $0.00 \%$ \\
\hline 6 & $6.67 \%$ & $20.19 \%$ & $0.00 \%$ & $0.05 \%$ & $0.00 \%$ \\
\hline 7 & $9.49 \%$ & $11.81 \%$ & $0.00 \%$ & $1.62 \%$ & $0.00 \%$ \\
\hline 8 & $8.96 \%$ & $13.79 \%$ & $0.00 \%$ & $1.62 \%$ & $0.00 \%$ \\
\hline 9 & $22.16 \%$ & $15.52 \%$ & $0.00 \%$ & $2.26 \%$ & $0.01 \%$ \\
\hline 10 & $17.64 \%$ & $23.15 \%$ & $0.00 \%$ & $3.07 \%$ & $0.00 \%$ \\
\hline \multicolumn{6}{|c|}{ Panel B: oil $\nrightarrow$ gold } \\
\hline Lag & $r$ & $R \boldsymbol{V}$ & $R J$ & RSK & $R K U$ \\
\hline 1 & $91.06 \%$ & $25.88 \%$ & $0.00 \%$ & $0.00 \%$ & $0.09 \%$ \\
\hline 2 & $94.43 \%$ & $41.71 \%$ & $0.00 \%$ & $0.00 \%$ & $0.14 \%$ \\
\hline 3 & $90.67 \%$ & $29.29 \%$ & $0.00 \%$ & $0.00 \%$ & $0.02 \%$ \\
\hline 4 & $31.67 \%$ & $18.18 \%$ & $0.00 \%$ & $0.00 \%$ & $0.05 \%$ \\
\hline
\end{tabular}




\begin{tabular}{lrrrrr}
$\mathbf{5}$ & $15.39 \%$ & $\mathbf{4 . 1 2 \%}$ & $\mathbf{0 . 0 0 \%}$ & $\mathbf{0 . 0 1 \%}$ & $\mathbf{0 . 3 4 \%}$ \\
$\mathbf{6}$ & $17.70 \%$ & $8.06 \%$ & $\mathbf{0 . 0 0 \%}$ & $\mathbf{0 . 0 3 \%}$ & $\mathbf{0 . 0 6 \%}$ \\
$\mathbf{7}$ & $17.46 \%$ & $14.86 \%$ & $\mathbf{0 . 0 0 \%}$ & $\mathbf{0 . 0 4 \%}$ & $\mathbf{0 . 0 7 \%}$ \\
$\mathbf{8}$ & $16.65 \%$ & $18.93 \%$ & $\mathbf{0 . 0 0 \%}$ & $\mathbf{0 . 2 8 \%}$ & $\mathbf{0 . 4 8 \%}$ \\
$\mathbf{9}$ & $24.42 \%$ & $21.77 \%$ & $\mathbf{0 . 0 0 \%}$ & $\mathbf{0 . 8 2 \%}$ & $\mathbf{4 . 8 3 \%}$ \\
$\mathbf{1 0}$ & $40.26 \%$ & $34.79 \%$ & $\mathbf{0 . 0 0 \%}$ & $\mathbf{0 . 6 7 \%}$ & $\mathbf{0 . 0 6 \%}$ \\
\hline
\end{tabular}

Note: See Notes to Table 1.

\subsection{Rolling-Window Causality Analysis}

To motivate the rolling-window causality test, we conducted tests of multiple structural breaks on the individual equations of the $\operatorname{VAR}(p)$ model used for the linear Granger causality test. In this regard, we applied the multiple structural break test of Bai and Perron (2003), and the change-point test of Horvath et al. (2017). The results have been reported in Tables B3 and B4 in the Appendix B respectively, and in general shows regimes changes for higher moments rather than returns (and realized volatility under the change point test). Not surprisingly, the break dates are concentrated around the global financial crisis, the European sovereign debt crisis, and the decline in oil prices of 2014. The structural breaks, as well as nonlinearity, warrants the need for a time-varying causality approach for our variables of concern.

Following Bampinas and Panagiotidis (2015), we perform a rolling-window study on the causality between the various metrics of gold and oil, based on the Hill (2007) framework with a bivariate VAR at horizon one. ${ }^{7}$ The rolling window length is set to be 522 days (close to 2 years of daily data), giving total number of widows equal to 5241. The causality analysis is carried out for each rolling-window, and we generated both parametric and bootstrapped $p$-values. We collect the number of rejections at $5 \%$ significance level, and then calculate the rejection rate, which is basically the number of rejections divided by the total number of windows, shown in Table 3. It is worthwhile to clarify that the numbers in Table 3 are the rejection rates, rather than $p$-values, and thus a larger number means rejecting the

\footnotetext{
${ }^{7}$ Throughout this paper, the setting of Hill (2007) test is as follows: 1) the maximum lag length of VAR is 15; 2) the optimal lag length of VAR is selected by BIC; 3) the bootstrap repetition is set to be 500 times.
} 
non-causality more frequently, which implies that the causality occurs in a large percentage of total number of windows.

The parametric and the bootstrap methods produce similar rejection rates, though the bootstrap $p$-values should have better approximation to the significance level under the null. We can hardly find casualty in both directions for the returns. Regarding $R V$, we find casualty in both direction among most of the rolling windows. This result is consistent with the linear causality analysis, but does not generally agree with the nonlinear test. In terms of $R J$, we can find roughly $25 \%$ of the rolling windows with causality in both directions. When we focus on $R S K$, we find very rare causality in the rolling windows from gold to oil, and $9 \%$ of the rolling windows with causality in the opposite direction. This result is understandable as the crash-risk measured by RSK, is likely to be especially low for gold, given its well-established role as a safe haven. We can obverse causality in about $6 \%$ of rolling windows for the $R K U$ in the direction from gold to oil, but $12 \%$ in the opposite direction. In summary, although nonlinear causality analysis suggests causality in $R J, R S K$, and $R K U$, the rolling window causality analyses reveal that the causality only occurs in certain specific periods to drive the overall results under the nonlinear tests.

Table 3. Rejection Rates of Rolling Window Causality

\begin{tabular}{lcccc}
\hline & \multicolumn{2}{c}{ gold $\nrightarrow$ oil } & \multicolumn{2}{c}{ oil $\nrightarrow$ gold } \\
& Parametric & Bootstrap & Parametric & Bootstrap \\
\hline $\boldsymbol{R}$ & $0.90 \%$ & $1.01 \%$ & $2.96 \%$ & $3.07 \%$ \\
$\boldsymbol{R} \boldsymbol{V}$ & $79.97 \%$ & $72.68 \%$ & $77.94 \%$ & $75.73 \%$ \\
$\boldsymbol{R} \boldsymbol{R}$ & $29.98 \%$ & $29.31 \%$ & $24.96 \%$ & $24.61 \%$ \\
$\boldsymbol{R} \boldsymbol{K}$ & $0.06 \%$ & $0.31 \%$ & $9.25 \%$ & $9.29 \%$ \\
$\boldsymbol{R} \boldsymbol{K} \boldsymbol{N}$ & $6.22 \%$ & $5.88 \%$ & $12.27 \%$ & $12.17 \%$ \\
\hline
\end{tabular}

Note: See Notes to Table 1; a larger number of rejection rate indicates a higher frequency of causality in the sample period.

In order to reveal the exact timing where the causality occurs, we plot the bootstrapped $p$-values of the rolling window causality test in Figures 1 to 5 . Firstly, we can observe that the $p$-values of causality of returns in both directions are mostly above 5\%, with some weak evidence observed in both directions in an intermittent fashion. Secondly, the causality in $R V$ is significant in the majority of the sample periods, but it is insignificant before 2002, during 2007 and 2012, and after 2015. Thirdly, the causality in $R J$ is mainly significant in 2006 and 2007. Fourthly, the causality in $R S K$ from oil to gold is significant 
before 2001, while the opposite direction is typically insignificant. Lastly, the causality in $R K U$ is significant only occasionally in the sample period around 2002, 2005 and 2012, primarily from gold to oil, and the other way round during the end of the sample period. In sum then, consistent with the linear causality, the evidence of spillover across the volatilities of the two markets are quite strong especially during periods of turmoil, ${ }^{8}$ with jumps (primarily associated with negative returns (bad) volatility) playing an important role in this process, as observed for the linear and nonlinear tests of causality earlier. ${ }^{9}$ Based on the similar rejection rates of non-causality when compared within the various metrics of gold and oil tends to suggest that these two markets are equally likely to affect each other in various dimensions, though the period during which this happens is likely to differ.

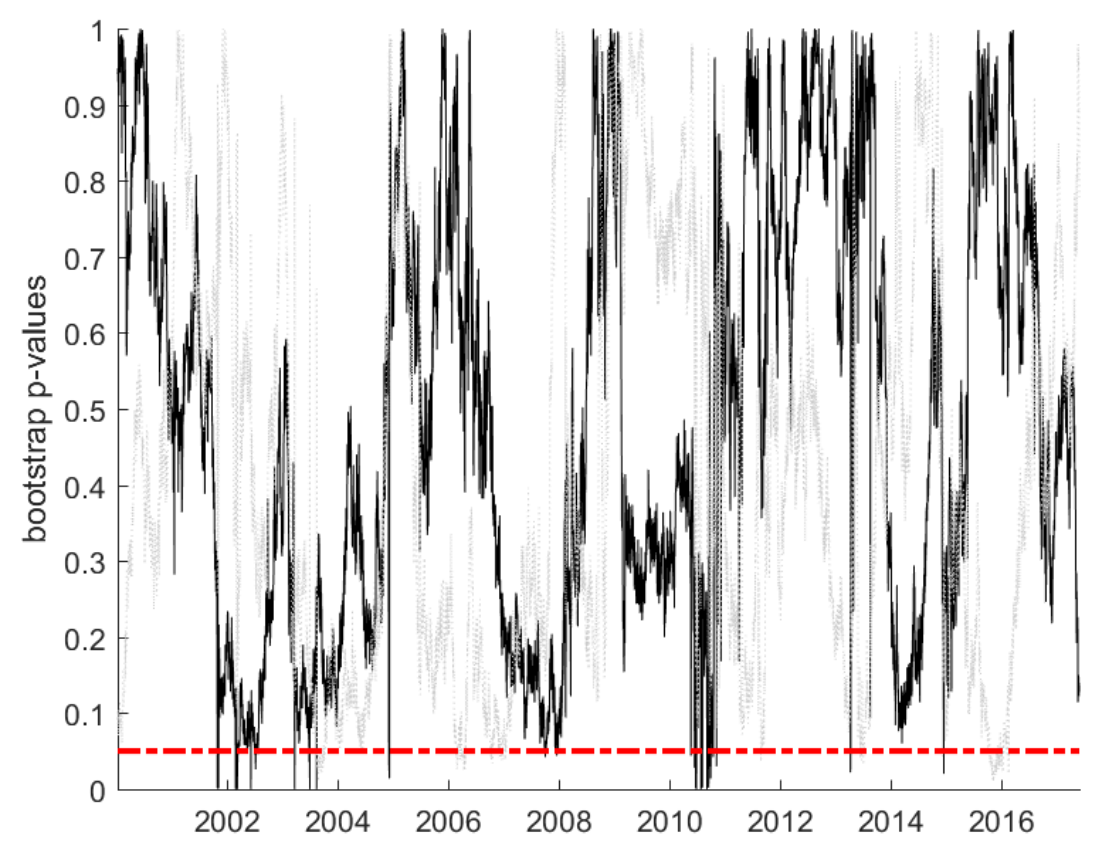

Figure 1. Rolling-Window Causality of Returns $(r)$

Note: Gold $\nrightarrow$ Oil (black line) and Oil $\nrightarrow$ Gold (grey line) bootstrap $p$-values for rolling-window causality analysis. The red horizontal line denotes the $5 \%$ significance level.

\footnotetext{
${ }^{8}$ The importance of volatility spillovers is in line with the indirect suggestion made by Bampinas and Panagiotidis (2015) in terms of causality of volatility. These authors showed that when the returns are filtered by a GARCHBEKK $(1,1)$ model, then causality between gold and oil returns no longer exists under the Diks and Panchenko (2006) framework, implying that nonlinear causality is due to volatility effects.

${ }^{9}$ The relatively stronger rejection rates under realized bad volatility compared to realized good volatility (particularly from gold to oil), results of which are available upon request from the authors, confirmed our conclusions associated with causality in $R J$.
} 


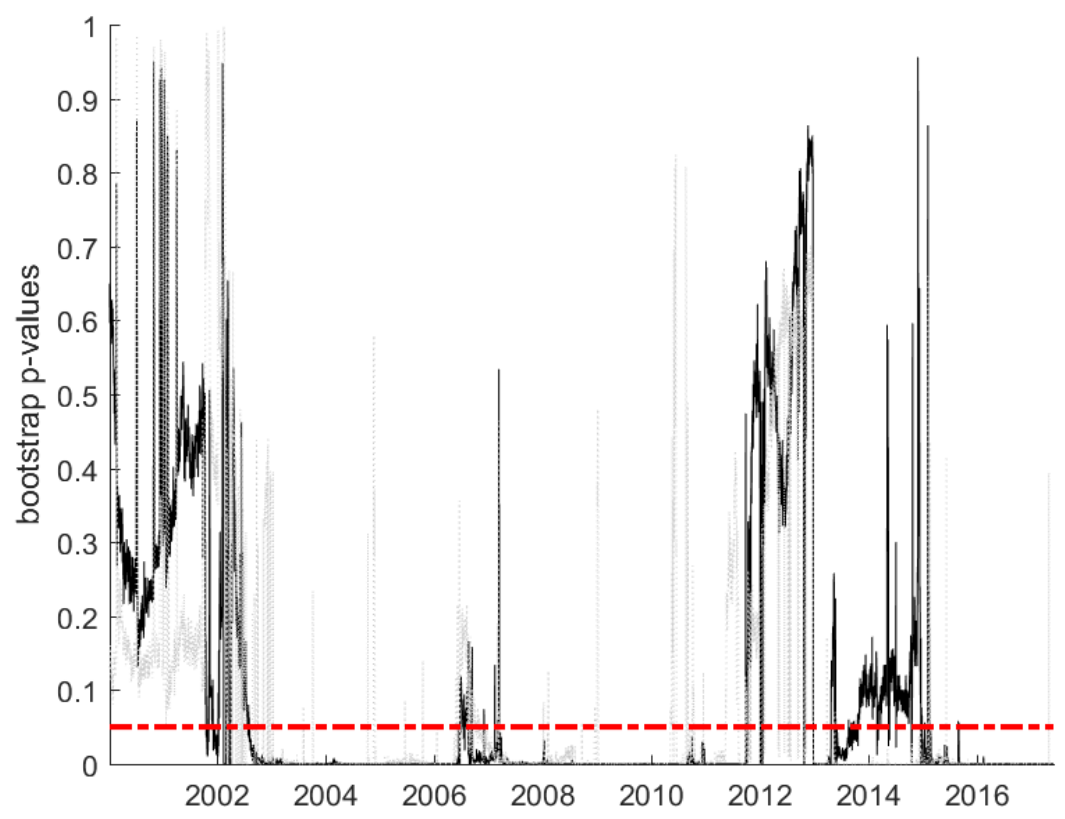

Figure 2. Rolling-Window Causality of Realized Volatility $(R V)$ Note: See Notes to Figure 1.

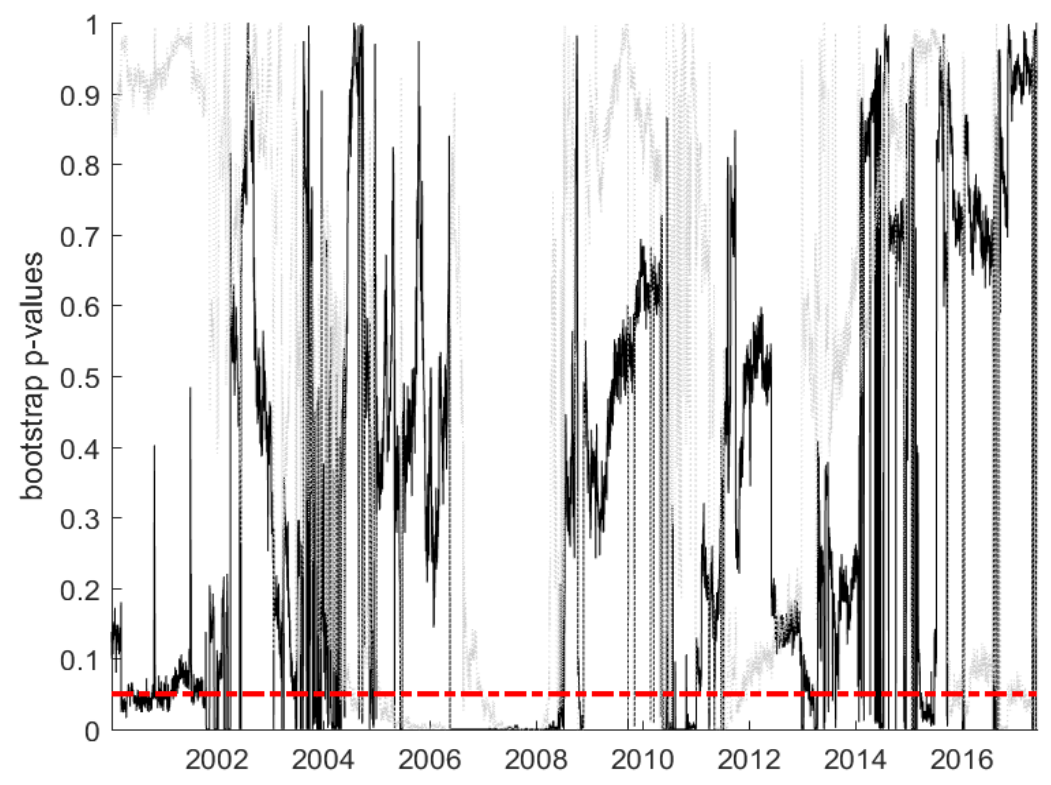

Figure 3. Rolling-Window Causality of Jumps $(R J)$

Note: See Notes to Figure 1. 


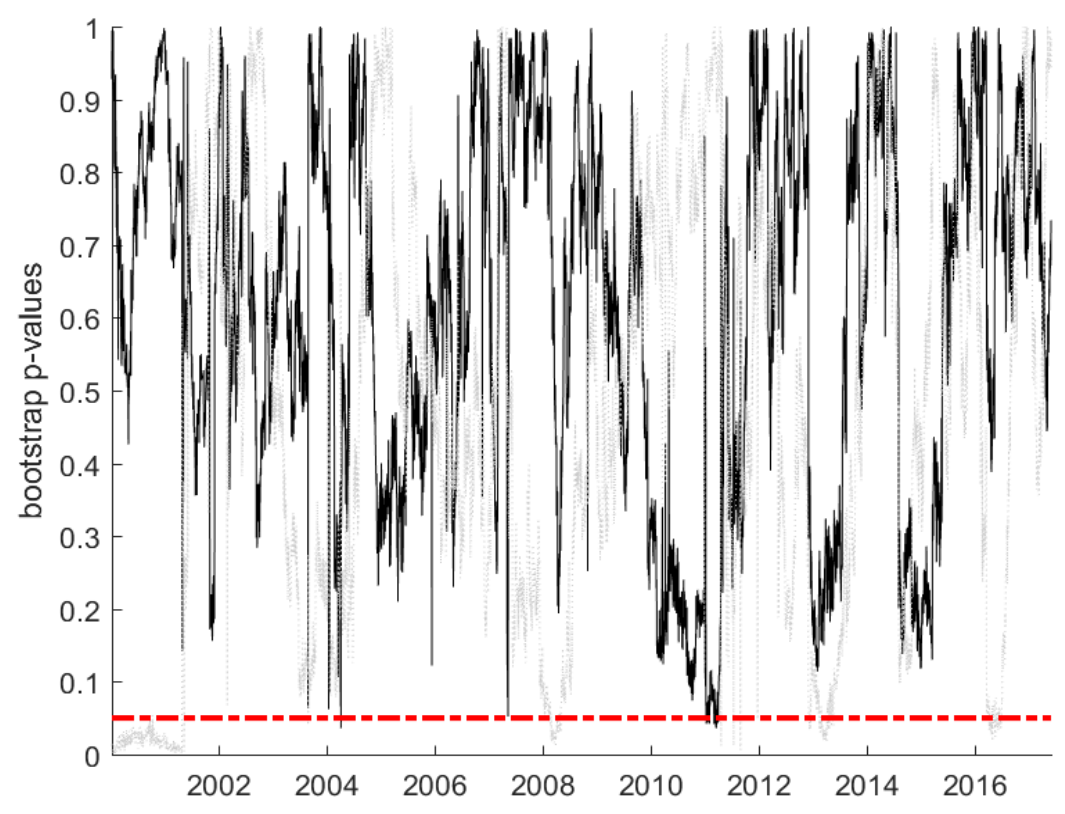

Figure 4. Rolling-Window Causality of Realized Skewness (RSK) Note: See Notes to Figure 1.

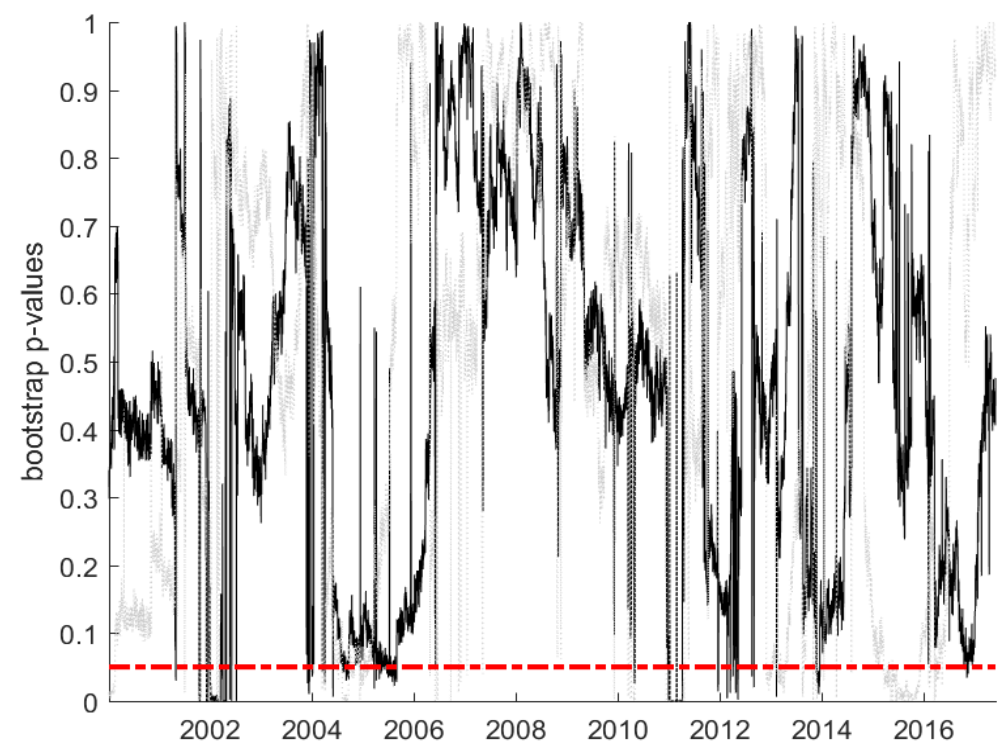

Figure 5. Rolling-Window Causality of Realized Kurtosis (RKU) Note: See Notes to Figure 1. 


\subsection{Causality-in-Moments Analysis}

Given the possibility of Granger causality in the cross moments (and quantiles), we expand our analysis by using the return series to perform the casualty in mean, variance, quantiles and more importantly, their cross-causality, as suggested by Chen (2016).

Before applying the test, it is important to specify the conditional model for $y_{i t} \mid \mathfrak{Y}_{i, t-1}$. Following Chen (2016), we use the AR(1)-GARCH(1,1) as the basic model for the first two moments and AR(1)GARCH(1,1)-APD, developed by Komunjer (2007), as the model for the quantiles and higher moments. The lags in the generalized cross-causality, $n$, is set to be up to 1,5 , and 10 . We consider the causality in five quantiles and denote them as $q 1$ (0-0.2); $q 2$ (0.2-0.4); $q 3$ (0.4-0.6); $q 4$ (0.6-0.8); and $q 5$ (0.8-1). Table 4 shows the $p$-values of the causality test in mean, variance, quantiles and their cross-causality, as developed by Chen (2016). The results of causality in mean is consistent with the three previous tests, i.e. there is no causality. Note, our results of lack in causality across the returns of the two markets is quite different from that of the recent work of Bampinas and Panagiotidis (2015), who, using linear, nonparametric and rolling-window causality tests like we use above, found that oil returns consistently caused gold returns, but the reverse is only true during episodes of crisis. But, it must be realized that, unlike these authors, we are focussing on futures prices, rather than spot prices, which makes our paper more relevant for practical applications in the context of hedging and/or safe-haven analyses, given the low transaction costs associated with futures trading. Furthermore, one can expect price discovery to take place primarily in the futures market as these prices respond to new information faster than the spot price due to lower transaction costs and ease of short selling associated with the futures contracts (Shrestha, 2014). This in turn, could be resulting in no impact on returns, but effects on higher moments through faster trading.

However, we find cross-causality from the first moment of gold to the second moment and some higher quantiles of oil ( $q 3, q 4$, and q5) and, in the opposite direction, from the first moment of oil to the second moment of gold. The causality in variance can only be found from gold to oil, but there is no crosscausality with the first moment and any quantiles. Interestingly, there is a strong cross-causality in q1 and the second moment in both directions. This is expected and can be easily explained by the fact that 
$q 1$ is the left tail of returns associated with negative shocks to the markets, and therefore has a significant impact on the second moment. Following the same logic, we also find the cross-causality in $q 5$ and the second moment. ${ }^{10}$

Overall, these results are in line with the idea of (partial) co-volatility spillovers, since the returns shock from financial asset $k$ affects the co-volatility between two financial assets, $i$ and $j$, one of which can be asset $k$ (Chang et al., 2018b).

Table 4. $p$-Values of Casualty-in-Moments Test

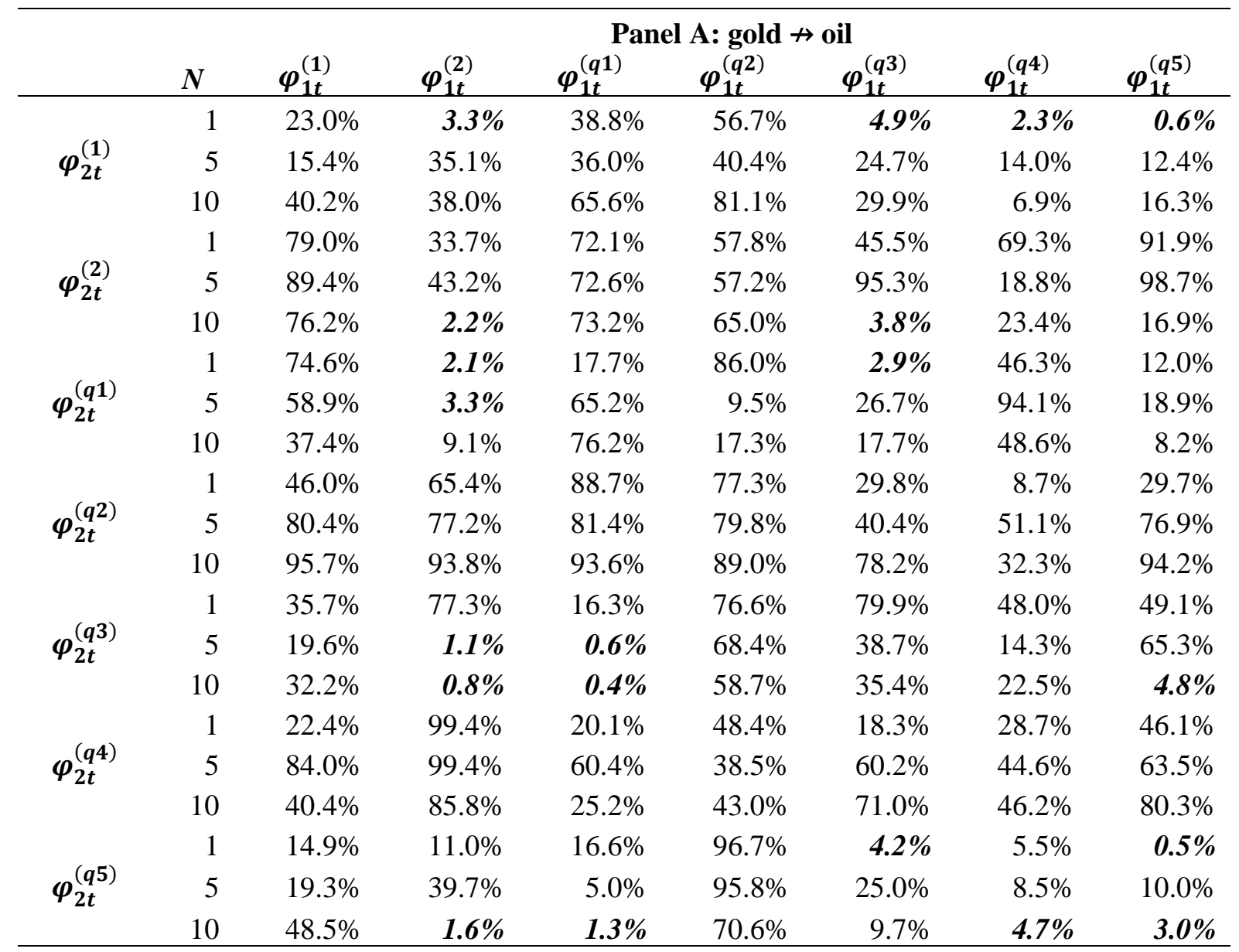

Panel B: oil $\nrightarrow$ gold

\begin{tabular}{rrrrrrrrr} 
& \multicolumn{1}{c}{$\boldsymbol{N}$} & $\boldsymbol{\varphi}_{1 t}^{(\mathbf{1})}$ & \multicolumn{1}{c}{$\boldsymbol{\varphi}_{\mathbf{1 t}}^{(\mathbf{2})}$} & $\boldsymbol{\varphi}_{1 t}^{(\boldsymbol{q} \mathbf{1})}$ & $\boldsymbol{\varphi}_{1 t}^{(\boldsymbol{q} \mathbf{2})}$ & $\boldsymbol{\varphi}_{1 t}^{(\boldsymbol{q} \mathbf{3})}$ & $\boldsymbol{\varphi}_{\mathbf{1 t}}^{(\boldsymbol{q} \mathbf{4})}$ & \multicolumn{1}{c}{$\boldsymbol{\varphi}_{1 t}^{(\boldsymbol{q} \mathbf{5})}$} \\
\hline \multirow{4}{*}{$\boldsymbol{\varphi}_{\mathbf{2 t}}^{(\mathbf{1})}$} & 1 & $32.7 \%$ & $18.5 \%$ & $69.1 \%$ & $33.2 \%$ & $45.1 \%$ & $42.4 \%$ & $16.6 \%$ \\
& 5 & $27.5 \%$ & $\mathbf{0 . 4 \%}$ & $10.5 \%$ & $74.2 \%$ & $33.0 \%$ & $95.9 \%$ & $13.6 \%$ \\
& 10 & $37.8 \%$ & $\mathbf{4 . 4 \%}$ & $38.3 \%$ & $28.5 \%$ & $37.1 \%$ & $98.6 \%$ & $8.4 \%$ \\
& 1 & $49.0 \%$ & $80.9 \%$ & $88.6 \%$ & $38.5 \%$ & $81.1 \%$ & $70.7 \%$ & $48.1 \%$
\end{tabular}

${ }^{10}$ In Table B5 in the Appendix B of the paper, we report the results from the out-of-sample version of Chen's (2016) test, with a spilt of $70 \%$ of the data as in-sample and the remaining $30 \%$ as the out-of-sample, as in the original paper. As can be seen from Table B5, our results are qualitatively similar, with the main conclusion still holding over the out-of-sample period of January 2, 2012 to May 26, 2017. 


\begin{tabular}{|c|c|c|c|c|c|c|c|c|}
\hline \multirow{2}{*}{$\varphi_{2 t}^{(2)}$} & 5 & $64.8 \%$ & $32.5 \%$ & $39.4 \%$ & $23.8 \%$ & $77.6 \%$ & $76.8 \%$ & $38.3 \%$ \\
\hline & 10 & $80.6 \%$ & $8.1 \%$ & $5.0 \%$ & $25.6 \%$ & $12.1 \%$ & $32.3 \%$ & $13.9 \%$ \\
\hline \multirow{3}{*}{$\varphi_{2 t}^{(q 1)}$} & 1 & $64.5 \%$ & $2.1 \%$ & $64.3 \%$ & $18.6 \%$ & $49.1 \%$ & $30.3 \%$ & $25.6 \%$ \\
\hline & 5 & $32.4 \%$ & $0.6 \%$ & $2.1 \%$ & $52.4 \%$ & $8.6 \%$ & $74.5 \%$ & $25.5 \%$ \\
\hline & 10 & $66.8 \%$ & $1.3 \%$ & $4.2 \%$ & $50.4 \%$ & $14.0 \%$ & $55.0 \%$ & $1.9 \%$ \\
\hline \multirow{3}{*}{$\varphi_{2 t}^{(q 2)}$} & 1 & $34.1 \%$ & $26.5 \%$ & $6.2 \%$ & $2.4 \%$ & $84.4 \%$ & $44.7 \%$ & $66.9 \%$ \\
\hline & 5 & $49.6 \%$ & $49.2 \%$ & $20.8 \%$ & $18.9 \%$ & $99.3 \%$ & $79.0 \%$ & $72.3 \%$ \\
\hline & 10 & $43.8 \%$ & $64.0 \%$ & $32.5 \%$ & $19.3 \%$ & $26.8 \%$ & $27.8 \%$ & $0.1 \%$ \\
\hline \multirow{3}{*}{$\varphi_{2 t}^{(q 3)}$} & 1 & $20.7 \%$ & $2.9 \%$ & $98.7 \%$ & $10.5 \%$ & $22.3 \%$ & $2.9 \%$ & $63.4 \%$ \\
\hline & 5 & $0.3 \%$ & $8.4 \%$ & $8.3 \%$ & $19.0 \%$ & $0.4 \%$ & $31.8 \%$ & $5.5 \%$ \\
\hline & 10 & $1.0 \%$ & $9.2 \%$ & $18.2 \%$ & $52.4 \%$ & $0.1 \%$ & $40.4 \%$ & $25.8 \%$ \\
\hline \multirow{3}{*}{$\varphi_{2 t}^{(q 4)}$} & 1 & $0.2 \%$ & $82.4 \%$ & $5.2 \%$ & $37.6 \%$ & $87.8 \%$ & $25.3 \%$ & $5.2 \%$ \\
\hline & 5 & $8.0 \%$ & $28.2 \%$ & $34.2 \%$ & $24.0 \%$ & $82.9 \%$ & $84.6 \%$ & $46.9 \%$ \\
\hline & 10 & $21.3 \%$ & $49.4 \%$ & $76.3 \%$ & $32.6 \%$ & $39.6 \%$ & $94.2 \%$ & $20.4 \%$ \\
\hline \multirow{3}{*}{$\varphi_{2 t}^{(q 5)}$} & 1 & $59.7 \%$ & $88.2 \%$ & $53.0 \%$ & $68.3 \%$ & $61.1 \%$ & $50.0 \%$ & $86.7 \%$ \\
\hline & 5 & $41.6 \%$ & $0.6 \%$ & $54.1 \%$ & $38.7 \%$ & $50.4 \%$ & $89.8 \%$ & $25.7 \%$ \\
\hline & 10 & $21.7 \%$ & $7.4 \%$ & $79.9 \%$ & $48.5 \%$ & $5.3 \%$ & $97.8 \%$ & $16.1 \%$ \\
\hline
\end{tabular}

Note: $\phi_{i t}^{(1)}$ is the first moment, $\phi_{i t}^{(2)}$ is the second moment, $\phi_{i t}^{(q 1)}$ is the quantile of $(0,0.2), \phi_{i t}^{(q 2)}$ is the quantile of $(0.2,0.4), \phi_{i t}^{(q 3)}$ is the quantile of $(0.4,0.6), \phi_{i t}^{(q 4)}$ is the quantile of $(0.6,0.8)$, and $\phi_{i t}^{(q 5)}$ is the quantile of $(0.8,1)$.

\section{Robustness Check}

In order to check the robustness of the causality between gold and oil, we employ the trivariate setting of Hill (2007) causality test with one auxiliary variable. Literatures suggest that the causality between gold and oil may be subject to other variables, such as "safe-heaven” currencies, in our case the Swiss Franc (Balcilar et al., forthcoming), sentiment (Balcilar et al., 2017), and financial stress (Das et al., 2018). We will consider them as the auxiliary variable in the framework of Hill (2007) trivariate causality test. We are interested in whether adding an auxiliary variable can change the causality relationship obtained in Section 4.

\subsection{Trivariate Causality among Gold, Oil, and CHF}

There are many assets, other than gold, which are also deemed as the "safe-heaven". We investigate whether any other assets that are generally considered as "safe" could play a role in the causality between gold and oil. To this end, we download the intraday return of Swiss Franc (CHF) ${ }^{11}$ and

\footnotetext{
${ }^{11}$ Data for which is obtained from $\pi$-Trading.com (https://pitrading.com/historical-market-data.html). Due to the data availability, we restrict the period to July 1 $1^{\text {st }}, 2003$ to August $28^{\text {th }}$, 2015.
} 
calculate its RV, RJ, RSK, and RKU. We use the relevant moment of CHF as the auxiliary variable in Hill (2007) framework to study the causality of various moments between gold and oil. ${ }^{12}$

Table 5 presents the $p$-values of the Hill (2007) test results with CHF as the auxiliary variable. There is strong evidence of bidirectional causality (rejection of Test 0.1 and 0.2 ) between gold and oil in terms of their RV and RJ, and such bidirectional causality is believed to be direct (rejection of Test 1.0), rather than a causal chain. This direct causality in both directions can lasts for at least five days (rejection of Test 2.0-5.0 at bounded 5\% level).

Additionally, we obtain the evidence of broken causal chains from gold to oil in terms of their return and RSK. Specifically, gold can cause CHF, yet CHF does not cause oil (rejection of 1.1; no rejection of 1.2), and thus a causal chain from gold to oil via CHF cannot be established. Regarding RSK and RKU in the direction from oil to gold, there is no evidence of direct causality or causal chain (no rejection of Test $0.1,0.2$, and 1.0-1.2).

It is interesting to observe that return of oil cannot cause the return of gold in any horizon (no rejection of Test 0.1 and 0.2 ) but Test 1.0 is still rejected at the same time. Such kind of conflict also appeared in Hill (2007) and Salamaliki and Venetis (2013). ${ }^{13}$ Strictly speaking, Hill (2007, p755) stipulate that “if both hypotheses are rejected then proceed to test for horizon-specific non-causation”, and the result of Test 0.1 and 0.2 should be prioritized over Test 1.0-1.2. Thus, we conclude that there is no evidence of causality from return of oil to return of gold at any horizon.

\footnotetext{
${ }^{12}$ For example, RV of CHF is the auxiliary variable when analyse the causality between RV of gold and oil. ${ }^{13}$ Hill (2007) allowed for simultaneous detection of non-causality at all horizons $Y \stackrel{(\infty)}{\rightarrow} X$ and causality at some horizon, $Y \stackrel{h}{\rightarrow} X$, in their empirical study of causality between M1 and real income. Salamaliki and Venetis (2013) employed Hill (2007) test to study the causality between energy consumption and real GDP, and their result also indicate the possible conflict between non-causality at all horizons and at some horizon.
} 


\subsection{Trivariate Causality among Gold, Oil, and Sentiment}

A number of papers have found that sentiment can have an impact on gold and oil return volatility (e.g. Balcilar et al, 2017). It is worthwhile to consider market sentiment as the auxiliary variable in the Hill (2007) test as well. Among different choices of sentiment measures, we select the Financial and Economic Attitudes Revealed by Search (FEARS) with thirty search terms, i.e. FEARS30, developed by Da et al. (2015). ${ }^{14}$ It should be noted that we always employ FEARS, rather than its higher moments which are unavailable, as the auxiliary variable to investigate the casualty between the different moments of gold and oil.

The $p$-values of Hill (2007) test with FEARS as the auxiliary variable are shown in Table 6. There is strong evidence of bidirectional causality between gold and oil of their RV and RKU (rejection of Test 0.1 and 0.2 ), and such causality relationship is direct (rejection of Test 1.0), which lasts for at least five days (rejection of Test 2.0-5.0 at bounded 5\% level). Focusing on RJ, the direct causality is found from oil to gold (rejection of Test 1.0), but not in the opposite direction which shows a broken casual chain (rejection of Test 1.1; no rejection of Test 1.2). Moreover, broken causal chains are also found in the return of gold and oil in both directions. There is no evidence of causality in any form for the RSK (no rejection of any test).

\section{3. $\quad$ Trivariate Causality among Gold, Oil, and Financial Stress}

Das et al. (2018) found that financial stress affects both returns and variance of gold and crude oil. Thus, financial stress can potentially change the casual relationship between gold and oil of their different moments. To investigate such issue, we choose the Office of Financial Research (OFR) Financial Stress Index (FSI) as the measure of the financial stress and treat it as the auxiliary variable in the Hill (2007)

\footnotetext{
${ }^{14}$ We download the data of FEARS from Zhi Da's website (https://www3.nd.edu/ zda/, accessed on February $23^{\text {rd }}, 2020$ ). Due the data availability, we restrict the period between July $1^{\text {st }}, 2004$ and December $30^{\text {th }}, 2011$. We also tried FEARS25 and FEARS35, and there is no difference in the conclusion of causality.
} 
test. ${ }^{15}$ Similar to Section 5.2, we employ FSI itself, rather than its higher moments, as the auxiliary variable.

Table 7 shows the $p$-values of Hill (2007) test with FSI as the auxiliary variable. The direct causality relationship can be observed in RV and RJ in both directions (rejection of Test $0.1,0.2$, and 1.0), while this direct causality only appears in RV from gold to oil. The broken causal chains are found in both direction of RSK and one direction of return from oil to gold (rejection of Test 1.0; no rejection of both Test 1.1 and 1.2).

It is noteworthy to point out that we find a causal chain in RV from oil to gold via FSI. This causal chain can be denoted as $R V$ of oil $\stackrel{1}{\rightarrow} F S I \stackrel{1}{\rightarrow} R V$ of gold. To elaborate on this casual chain, the RV of oil does not directly cause the RV of gold, and it is actual that the RV of oil firstly causes FSI and then FSI further cause the RV of gold. This observation is valuable in the sense that the volatility spillover from oil to gold is through the intermediary of FSI. Regarding the return series, the causal chain seems to be established from gold to oil, but however the rejection of Test 0.2 overrides the result, suggesting there is no causality at any horizon in this case.

In conclusion, the results from the Hill (2007) trivariate framework with different auxiliary variable are generally consistent with our findings in our Section 4. We can hardly find any causality in the returns and RSK of gold and oil, but the direct causality can be identified in most cases of RV, RJ, and RKU. The most valuable observation in this section is that we find a causal chain in RV from oil to gold via FSI, which cannot be revealed in any bivariate causality tests.

\footnotetext{
${ }^{15}$ We download the data of OFR FSI from the OFR website (https://www.financialresearch.gov/financial-stressindex, accessed on February $\left.23^{\text {rd }}, 2020\right)$. Due the data availability, we restrict the period between January $4^{\text {th }}$, 2000 and May 26 ${ }^{\text {th }}, 2017$.
} 
Table 5. p-values of Hill (2007) Trivariate Causality Test with CHF as the Auxiliary Variable

\begin{tabular}{|c|c|c|c|c|c|c|c|c|c|c|c|c|}
\hline & \multicolumn{9}{|c|}{ Test } & \multicolumn{3}{|c|}{ Conclusion on Causality } \\
\hline & 0.1 & 0.2 & 1.0 & 1.1 & 1.2 & 2.0 & 3.0 & 4.0 & 5.0 & Any horizon & Direct or Chain & Overall \\
\hline \multicolumn{13}{|c|}{ Panel A: gold $(Y) \nrightarrow$ oil $(X)$} \\
\hline$r$ & $11.00 \%$ & $14.20 \%$ & $51.40 \%$ & $0.00 \%$ & $6.20 \%$ & $12.00 \%$ & & & & $Y \stackrel{(\infty)}{\nrightarrow} X$ & $Y \stackrel{1}{\rightarrow} U \stackrel{1}{\rightarrow} X$ & $Y \stackrel{(\infty)}{\rightarrow} X$ \\
\hline$R V$ & $0.00 \%$ & $0.00 \%$ & $0.00 \%$ & $0.00 \%$ & $91.20 \%$ & $0.00 \%$ & $0.00 \%$ & $0.00 \%$ & $0.00 \%$ & $Y \stackrel{(\infty)}{\longrightarrow} X$ & $Y \stackrel{1}{\rightarrow} X$ & $Y \stackrel{1}{\rightarrow} X$ \\
\hline$R J$ & $0.00 \%$ & $0.00 \%$ & $0.00 \%$ & $0.00 \%$ & $47.00 \%$ & $0.00 \%$ & $0.00 \%$ & $0.00 \%$ & $0.00 \%$ & $Y \stackrel{(\infty)}{\longrightarrow} X$ & $Y \stackrel{1}{\rightarrow} X$ & $Y \stackrel{1}{\rightarrow} X$ \\
\hline RSK & $95.20 \%$ & $49.40 \%$ & $73.60 \%$ & $0.00 \%$ & $29.00 \%$ & $51.20 \%$ & & & & $Y \stackrel{(\infty)}{\rightarrow} X$ & $Y \stackrel{1}{\rightarrow} U \stackrel{1}{\rightarrow} X$ & $Y \stackrel{(\infty)}{\stackrel{+}{+}} X$ \\
\hline$R K U$ & $5.40 \%$ & $5.20 \%$ & $2.00 \%$ & $100.00 \%$ & $21.80 \%$ & $4.00 \%$ & & & & $Y \nrightarrow X$ & $Y \stackrel{\perp}{\rightarrow} X$ & $Y \nrightarrow X$ \\
\hline \multicolumn{13}{|c|}{ Panel B: oil $(\mathrm{Y}) \nrightarrow$ gold $(\mathrm{X})$} \\
\hline$r$ & $12.00 \%$ & $14.20 \%$ & $2.80 \%$ & $0.00 \%$ & $18.80 \%$ & $11.80 \%$ & & & & $Y \stackrel{(\infty)}{\rightarrow} X$ & $Y \stackrel{1}{\rightarrow} X$ & $Y \stackrel{(\infty)}{\rightarrow} X$ \\
\hline$R \boldsymbol{V}$ & $0.00 \%$ & $0.00 \%$ & $0.00 \%$ & $0.00 \%$ & $0.00 \%$ & $0.00 \%$ & $0.00 \%$ & $0.00 \%$ & $0.00 \%$ & $Y \stackrel{(\infty)}{\longrightarrow} X$ & $Y \stackrel{1}{\rightarrow} X$ & $Y \stackrel{1}{\rightarrow} X$ \\
\hline $\boldsymbol{R J}$ & $0.00 \%$ & $0.00 \%$ & $0.00 \%$ & $100.00 \%$ & $34.00 \%$ & $0.00 \%$ & $0.00 \%$ & $0.00 \%$ & $0.00 \%$ & $Y \stackrel{(\infty)}{\rightarrow} X$ & $Y \stackrel{1}{\rightarrow} X$ & $Y \stackrel{1}{\rightarrow} X$ \\
\hline RSK & $16.20 \%$ & $49.20 \%$ & $46.60 \%$ & $100.00 \%$ & $49.00 \%$ & $47.20 \%$ & & & & $Y \stackrel{(\infty)}{\rightarrow} X$ & $Y \stackrel{1}{\rightarrow} X ; Y \stackrel{1}{\rightarrow} U ; U \stackrel{1}{\rightarrow} X$ & $Y \stackrel{(\infty)}{\rightarrow} X$ \\
\hline$R K U$ & $61.80 \%$ & $28.80 \%$ & $39.80 \%$ & $100.00 \%$ & $10.80 \%$ & $28.60 \%$ & & & & $Y \stackrel{(\infty)}{\rightarrow} X$ & $Y \stackrel{1}{\rightarrow} X ; Y \stackrel{1}{\rightarrow} U ; U \stackrel{1}{\rightarrow} X$ & $Y \stackrel{(\infty)}{\rightarrow} X$ \\
\hline
\end{tabular}

Note: $p$-values in blue background are related to Step 1 of Hill (2007) test. Fail to reject either Test 0.1 or Test 0.2 implies the detection of non-causality at all horizons. Rejection in both Test 0.1 and 0.2 leads to proceed with the horizon-specific non-causality test. $p$-values in the yellow background are related to Step 2 of Hill (2007) test. Rejection of Test 1.0 suggests a direct causality from $Y$ to X at horizon one. Fail to reject Test 1.0 and reject both Test 1.1 and 1.2 indicates the presentence of a causal chain. $p$-values in the grey background are related to Step 3 of Hill (2007) test. Test 2.0-5.0 is for testing non-causality up to horizon $h \geq 2$. Bonferroni-type test size bound should be used in Step 3. In blue and yellow background, $p$-values in bold and italic font are significant at $5 \%$ level. In grey background, $p$-values in bold and italic font are significant at bounded $5 \%$ level. 
Table 6. p-values of Hill (2007) Trivariate Causality Test with FEARS as the Auxiliary Variable

\begin{tabular}{|c|c|c|c|c|c|c|c|c|c|c|c|c|}
\hline & \multicolumn{9}{|c|}{ Test } & \multicolumn{3}{|c|}{ Conclusion on Causality } \\
\hline & 0.1 & 0.2 & 1.0 & 1.1 & 1.2 & 2.0 & 3.0 & 4.0 & 5.0 & Any horizon & Direct or Chain & Overall \\
\hline \multicolumn{13}{|c|}{ Panel A: gold $(Y) \nrightarrow$ oil $(X)$} \\
\hline$r$ & $71.60 \%$ & $60.00 \%$ & $66.20 \%$ & $0.00 \%$ & $32.20 \%$ & $66.20 \%$ & & & & $Y \stackrel{(\infty)}{\oplus} X$ & $Y \stackrel{1}{\rightarrow} U \stackrel{1}{\rightarrow} X$ & $Y \stackrel{(\infty)}{\rightarrow} X$ \\
\hline $\boldsymbol{R} \boldsymbol{V}$ & $0.00 \%$ & $0.00 \%$ & $0.00 \%$ & $0.00 \%$ & $8.80 \%$ & $0.00 \%$ & $0.00 \%$ & $0.00 \%$ & $0.00 \%$ & $Y \underset{(\infty)}{\stackrel{(\infty)}{\longrightarrow}} X$ & $Y \stackrel{1}{\rightarrow} X$ & $Y \stackrel{1}{\rightarrow} X$ \\
\hline$R \boldsymbol{R}$ & $3.14 \%$ & $5.40 \%$ & $13.76 \%$ & $0.00 \%$ & $45.28 \%$ & $6.76 \%$ & $6.54 \%$ & $9.54 \%$ & $4.30 \%$ & $Y \stackrel{(\infty)}{\rightarrow} X$ & $Y \stackrel{1}{\rightarrow} U \stackrel{1}{\leftrightarrow} X$ & $Y \stackrel{(\infty)}{\rightarrow} X$ \\
\hline RSK & $99.00 \%$ & $97.40 \%$ & $91.00 \%$ & $100.00 \%$ & $89.60 \%$ & $98.60 \%$ & & & & $Y \rightarrow X$ & $Y \stackrel{\leftrightarrow}{\nrightarrow} X ; Y \stackrel{\leftrightarrow}{\nrightarrow} U ; U \stackrel{\leftrightarrow}{\nrightarrow} X$ & $Y \rightarrow X$ \\
\hline$R K U$ & $0.00 \%$ & $0.00 \%$ & $0.00 \%$ & $0.00 \%$ & $78.40 \%$ & $0.00 \%$ & $0.00 \%$ & $0.00 \%$ & $0.00 \%$ & $Y \stackrel{(\infty)}{\longrightarrow} X$ & $Y \stackrel{1}{\rightarrow} X$ & $Y \stackrel{1}{\rightarrow} X$ \\
\hline \multicolumn{13}{|c|}{ Panel B: oil $(Y) \nrightarrow$ gold $(X)$} \\
\hline$r$ & $23.20 \%$ & $91.00 \%$ & $87.40 \%$ & $0.00 \%$ & $68.00 \%$ & $89.80 \%$ & & & & $Y \stackrel{(\infty)}{\rightarrow} X$ & $Y \stackrel{1}{\rightarrow} U \stackrel{1}{\rightarrow} X$ & $Y \stackrel{(\infty)}{\rightarrow} X$ \\
\hline$R V$ & $0.00 \%$ & $0.00 \%$ & $0.00 \%$ & $0.00 \%$ & $1.80 \%$ & $0.60 \%$ & $0.20 \%$ & $0.00 \%$ & $0.20 \%$ & $Y \stackrel{(\infty)}{\longrightarrow} X$ & $Y \stackrel{1}{\rightarrow} X$ & $Y \stackrel{1}{\rightarrow} X$ \\
\hline$R J$ & $3.00 \%$ & $0.00 \%$ & $3.40 \%$ & $0.00 \%$ & $0.80 \%$ & $2.20 \%$ & $1.40 \%$ & $0.20 \%$ & $0.40 \%$ & $Y \stackrel{(\infty)}{\rightarrow} X$ & $Y \stackrel{1}{\rightarrow} X$ & $Y \stackrel{1}{\rightarrow} X$ \\
\hline RSK & $20.40 \%$ & $8.40 \%$ & $8.00 \%$ & $100.00 \%$ & $14.20 \%$ & $9.00 \%$ & & & & $Y \stackrel{(\infty)}{\nrightarrow} X$ & $Y \stackrel{1}{\rightarrow} X ; Y \stackrel{1}{\rightarrow} U ; U \stackrel{1}{\rightarrow} X$ & $Y \stackrel{(\infty)}{\nrightarrow} X$ \\
\hline$R K U$ & $3.40 \%$ & $4.40 \%$ & $0.20 \%$ & $100.00 \%$ & $79.20 \%$ & $0.60 \%$ & $0.60 \%$ & $1.00 \%$ & $0.20 \%$ & $Y \stackrel{(\infty)}{\longrightarrow} X$ & $Y \stackrel{1}{\rightarrow} X$ & $Y \stackrel{1}{\rightarrow} X$ \\
\hline
\end{tabular}


Table 7. p-values of Hill (2007) Trivariate Causality Test with FSI as the Auxiliary Variable

Test

Conclusion on Causality

\begin{tabular}{llllllllll}
0.1 & 0.2 & 1.0 & 1.1 & 1.2 & 2.0 & 3.0 & 4.0 & 5.0 & Any horizon \\
\hline
\end{tabular}

Panel A: gold $(\mathrm{Y}) \nrightarrow$ oil $(\mathrm{X})$

\begin{tabular}{|c|c|c|c|c|c|c|c|c|c|c|c|c|}
\hline$r$ & $0.80 \%$ & $60.00 \%$ & $67.80 \%$ & $0.00 \%$ & $0.00 \%$ & $26.40 \%$ & $42.40 \%$ & & & $Y \stackrel{(\infty)}{\rightarrow} X$ & $Y \stackrel{1}{\rightarrow} U \stackrel{1}{\rightarrow} X$ & $Y \stackrel{(\infty)}{\rightarrow} X$ \\
\hline $\boldsymbol{R V}$ & $0.00 \%$ & $0.00 \%$ & $0.00 \%$ & $0.00 \%$ & $0.00 \%$ & $0.00 \%$ & $0.00 \%$ & $0.00 \%$ & $0.00 \%$ & $Y \stackrel{(\infty)}{\rightarrow} X$ & $Y \stackrel{1}{\rightarrow} X$ & $Y \stackrel{1}{\rightarrow} X$ \\
\hline$R J$ & $0.00 \%$ & $0.00 \%$ & $0.00 \%$ & $0.00 \%$ & $0.00 \%$ & $0.00 \%$ & $0.00 \%$ & $0.00 \%$ & $0.00 \%$ & $Y \stackrel{(\infty)}{\rightarrow} X$ & $Y \stackrel{1}{\rightarrow} X$ & $Y \stackrel{1}{\rightarrow} X$ \\
\hline$R S K$ & $96.60 \%$ & $44.60 \%$ & $87.60 \%$ & $100.00 \%$ & $0.00 \%$ & $6.40 \%$ & $14.00 \%$ & & & $Y \stackrel{(\infty)}{\nrightarrow} X$ & $Y \stackrel{1}{\rightarrow} U \stackrel{1}{\rightarrow} X$ & $Y \stackrel{(\infty)}{\rightarrow} X$ \\
\hline$R K U$ & $0.00 \%$ & $0.00 \%$ & $0.00 \%$ & $100.00 \%$ & $0.00 \%$ & $0.00 \%$ & $0.00 \%$ & $0.00 \%$ & $0.00 \%$ & $Y \stackrel{(\infty)}{\longrightarrow} X$ & $Y \stackrel{1}{\rightarrow} X$ & $Y \stackrel{1}{\rightarrow} X$ \\
\hline
\end{tabular}

Panel B: oil (Y) $\rightarrow$ gold $(\mathrm{X})$

\begin{tabular}{|c|c|c|c|c|c|c|c|c|c|c|c|c|}
\hline & & & & & & & & & & $(\infty)$ & 1 & $(\infty)$ \\
\hline$r$ & $16.20 \%$ & $95.00 \%$ & $83.20 \%$ & $0.00 \%$ & $40.20 \%$ & $90.40 \%$ & $3.40 \%$ & & & $Y \nrightarrow X$ & $Y \nrightarrow U \nrightarrow X$ & $Y \nrightarrow X$ \\
\hline$R \boldsymbol{V}$ & $0.40 \%$ & $0.00 \%$ & $21.80 \%$ & $0.00 \%$ & $0.00 \%$ & $0.00 \%$ & $0.00 \%$ & $0.00 \%$ & $0.00 \%$ & $Y \stackrel{(\infty)}{\longrightarrow} X$ & $Y \stackrel{1}{\rightarrow} U \stackrel{1}{\rightarrow} X$ & $Y \stackrel{1}{\rightarrow} U \stackrel{1}{\rightarrow} X$ \\
\hline $\boldsymbol{R J}$ & $0.00 \%$ & $0.00 \%$ & $0.00 \%$ & $100.00 \%$ & $0.00 \%$ & $0.00 \%$ & $0.00 \%$ & $0.00 \%$ & $0.00 \%$ & $Y \stackrel{(\infty)}{\rightarrow} X$ & $Y \stackrel{1}{\rightarrow} X$ & $Y \stackrel{1}{\rightarrow} X$ \\
\hline RSK & $57.60 \%$ & $19.40 \%$ & $80.80 \%$ & $100.00 \%$ & $0.00 \%$ & $0.00 \%$ & $49.80 \%$ & & & $Y \stackrel{(\infty)}{\nrightarrow} X$ & $Y \stackrel{1}{\rightarrow} U \stackrel{1}{\rightarrow} X$ & $Y \stackrel{(\infty)}{\nrightarrow} X$ \\
\hline $\boldsymbol{R K U}$ & $0.40 \%$ & $0.20 \%$ & $0.00 \%$ & $100.00 \%$ & $2.80 \%$ & $0.00 \%$ & $0.00 \%$ & $0.00 \%$ & $0.00 \%$ & $Y \stackrel{(\infty)}{\longrightarrow} X$ & $Y \stackrel{1}{\rightarrow} X$ & $Y \stackrel{1}{\rightarrow} X$ \\
\hline
\end{tabular}

Note: See Notes to Table 5. 


\section{Concluding Remarks}

In this paper, we analyze the causal relationship between not only returns and overall variance of gold and oil markets, but also volatility jumps, skewness and kurtosis. In this regard, we use 5-minute futures market data on gold and oil returns, which are then used to compute realized volatility, jumps, realized skewness and kurtosis, over the daily period of December 2, 1997 to May 26, 2017. We then analyze the causal relationships between these metrics for gold and oil markets, using linear, nonparametric and time-varying approaches, with the latter two methods providing robust inferences in the presence of nonlinearity and structural breaks, which we show to exist between the variables of concern. In addition, we use a moments-based test of causality, which allows us to test for cross-casualty of returns, variances and quantiles. To check the robustness, we employ the trivariate causality test of Hill (2007) to investigate whether an additional auxiliary variable can have an impact on the causality between gold and oil.

We find that, while there is hardly any evidence of spillovers between the returns of these two markets, strong evidence of bidirectional causality is detected for realized volatility, which seems to be resulting from volatility jumps. Evidence of spillovers is also detected for the realized skewness and realized kurtosis as well, with the effect in terms of the latter being relatively stronger, suggesting spillovers during extreme market situations. Moreover, based on the moments-based test of causality, evidence of co-volatility is obtained, which implied that extreme positive and negative returns of gold and oil tend to drive the volatilities in these markets. Finally, the trivariate causality test suggests a causal chain in the realized volatility from oil to gold via the financial stress.

Our results are likely to have important implications for economic agents. In this regard, as highlighted in the introduction, recent studies have indicated that that using information on volatility jumps, realized skewness and realized kurtosis, investors can improve portfolio performance since these realized measures contain incremental information over simple realized variances. Naturally, our results have important implications for portfolio managers aiming to design optimal portfolios involving these two important commodities, since they will now have to take account of not only spillovers associated with realized volatility, but also, with those resulting between jumps (or bad volatility), and realized 
skewness and realized kurtosis capturing crash and extreme risks respectively. ${ }^{16}$ In addition, given that there is spillover of realized skewness, implies that the possibility of a bubble in one of these two major commodity markets, particularly from the oil market, is likely to spread to the other market as well, and with commodity markets historically considered as leading indicators of the macroeconomy (Stock and Watson, 2003; Plakandaras et al., 2017; Pierdzioch and Gupta, 2019), recessionary impacts could be deep and persistent when these bubbles burst. In light of this, policymakers would need to vigilant and design appropriate counteractive policies ahead of time based on this high-frequency information. Future research will investigate the specific portfolio benefits by taking the causality between higher moments of gold and oil into consideration.

\section{References}

Agyei-Ampomah, S., Gounopoulos, D., \& Mazouz, K. (2014). Does gold offer a better protection against losses in sovereign debt bonds than other metals?. Journal of Banking \& Finance, 40, 507-521.

Akram, Q. F. (2009). Commodity prices, interest rates and the dollar. Energy Economics, 31(6), 838-851.

Amaya, D., Christoffersen, P., Jacobs, K., and Vasquez, A. (2015). Does realized skewness predict the cross-section of equity returns? Journal of Financial Economics, 118, 135-167.

Andersen T.G., \& Bollerslev T. (1998). Answering the Skeptics: Yes, Standard Volatility Models Do Provide Accurate Forecasts. International Economic Review, 39(4), 885-905.

Andersen, T.G., Bollerslev, T., \& Diebold, F.X. (2007). Roughing it up: including jump components in the measurement, modeling, and forecasting of return volatility. The Review of Economics and Statistics, 89(4), 701-720.

Antonakakis, N., Cunado, J., Filis, G., Gabauer, D., \& De Gracia, F. P. (2018). Oil Volatility, Oil and Gas Firms And Portfolio Diversification. Energy Economics, 70, 499-515.

Asai, M., Gupta, R., \& McAleer, M. (Forthcoming). The Impact of Jumps and Leverage in Forecasting the Co-Volatility of Oil and Gold Futures. Energies.

Bahloul, W., Balcilar, M., Cunado, J., \& Gupta, R. (2018). The role of economic and financial uncertainties in predicting commodity futures returns and volatility: Evidence from a nonparametric causality-in-quantiles test. Journal of Multinational Financial Management, 45, 52-71.

Bai, J. \& Perron, P. (2003). Computation and analysis of multiple structural change models. Journal of Applied Econometrics, 18, 1-22.

Balcilar, M., Bonato, M., Demirer, R., and Gupta, R. (2017). The effect of investor sentiment on gold market return dynamics: Evidence from a nonparametric causality-in-quantiles approach. Resources Policy, 51, 77-84.

Balcilar, M., Demirer, R., \& Gupta, R. (2017). Do Sustainable Stocks Offer Diversification Benefits for Conventional Portfolios? An Empirical Analysis of Risk Spillovers and Dynamic Correlations. Sustainability, 9, 1799.

\footnotetext{
${ }^{16}$ As for the specific techniques of portfolio optimization with higher moments, we direct readers to Harvey et al. (2010) and Jondeau and Rockinger (2006). This could indeed be an interesting area of future research, as it is beyond the scope of the current paper.
} 
Balcilar, M., Demirer, R., Gupta, R., \& Wohar, M.E. (Forthcoming). Time-Varying spillovers between Safe Havens and Global and Regional Stock Markets. Structural Change and Economic Dynamics.

Balcilar, M., Gupta, R., \& Pierdzioch, C. (2016). Does uncertainty move the gold price? New evidence from a nonparametric causality-in-quantiles test. Resources Policy, 49, 74-80.

Balcilar, M., Ozdemir, Z. A., \& Shahbaz, M. (2019). On the time-varying links between oil and gold: New insights from the rolling and recursive rolling approaches. International Journal of Finance \& Economics, 24(3), 1047-1065.

Balcilar, M., Ozdemir, Z.A. \& Arslanturk, Y. (2010). Economic growth and energy consumption causal nexus viewed through a bootstrap rolling window. Energy Economics, 32, 1398-1410.

Bampinas, G., \& Panagiotidis, T. (2015). On the relationship between oil and gold before and after financial crisis: linear, nonlinear and time-varying causality testing. Studies in Nonlinear Dynamics \& Econometrics, 19(5), 657-668.

Barndorff-Nielsen, O.E. \& Shephard, N. (2004). Power and Bipower Variation with Stochastic Volatility and Jumps. Journal of Financial Econometrics, 2, 1-37.

Barndorff-Nielsen, O.E. \& Shephard, N. (2006). Econometrics of Testing for Jumps in Financial Economics using Bipower Variation. Journal of Financial Econometrics, 4, 1-30.

Baur, D. G., \& Lucey, B. M. (2010). Is gold a hedge or a safe haven? An analysis of stocks, bonds and gold. Financial Review, 45(2), 217-229.

Baur, D. G., \& McDermott, T. K. (2010). Is gold a safe haven? International evidence. Journal of Banking \& Finance, 34(8), 1886-1898.

Beckmann, J., Berger, T., \& Czudaj, R. (2015). Does gold act as a hedge or a safe haven for stocks? A smooth transition approach. Economic Modelling, 48, 16-24.

Beckmann, J., Berger, T., \& Czudaj, R. (2019). Gold price dynamics and the role of uncertainty. Quantitative Finance, 19(4), 663-681.

Ben Nasr, A., Bonato, M., Demirer, R., and Gupta, R. (2019). Investor Sentiment and Crash Risk in Safe Havens. Journal of Economics and Behavioral Studies, 10(6A), 97-108.

Bilgin, M. H., Gogolin, F., Lau, C. K. M., \& Vigne, S. A. (2018). Time-variation in the relationship between white precious metals and inflation: A cross-country analysis. Journal of International Financial Markets Institutions, and Money, 56, 55-70.

Bilgin, M. H., Gozgor, G., Lau, C. K. M., \& Sheng, X. (2018). The effects of uncertainty measures on the price of gold. International Review of Financial Analysis, 58, 1-7.

Bollerslev, T., Kretschmer, U., Pigorsch, C., \& Tauchen, G. (2009). A discrete-time model for daily S \& P500 returns and realized variations: Jumps and leverage effects. Journal of Econometrics, 150(2), 151-166.

Bonato, M. (2019). Realized correlations, betas and volatility spillover in the agricultural commodity market: What has changed? Journal of International Financial Markets, Institutions and Money. DOI: https://doi.org/10.1016/j.intfin.2019.07.005.

Bonato, M., \& Taschini, L. (2016). Comovement and the financialization of commodities. Grantham Research Institute on Climate Change and the Environment Working Paper No. 215.

Bouoiyour, J., Selmi, R., \& Wohar, M. E. (2018). Measuring the response of gold prices to uncertainty: An analysis beyond the mean. Economic Modelling, 75, 105-116.

Brock, W., Dechert, D., Scheinkman, J. \& LeBaron, B. (1996). A test for independence based on the correlation dimension. Econometric Reviews, 15, 197-235.

Büyükşahin, B., \& Robe, M. A. (2014). Speculators, commodities and cross-market linkages. Journal of International Money and Finance, 42, 38-70.

Caporin, M., Rossi, E., \& Santucci de Magistris, P. (2016). Volatility jumps and their economic determinants. Journal of Financial Econometrics, 14, 29-80. 
Chang, C.-L. , McAleer, M., \& Wang, Y. (2018a). Testing Co-volatility Spillovers for Natural Gas Spot, Futures and ETF Spot using Dynamic Conditional Covariances. Energy, 151, 984-997.

Chang, C.-L., Li, Y.-Y., \& McAleer, M. (2018b). Volatility Spillovers between Energy and Agricultural Markets: A Critical Appraisal of Theory and Practice. Energies, 11(6:1595), 119.

Chen, Y-T. (2016). Testing for Granger Causality in Moments. Oxford Bulletin of Economics and Statistics, 78(2), 265-288.

Coronado, S., \& Jiménez-Rodríguez, R., \& Rojas, O. (2018). An Empirical Analysis of the Relationships between Crude Oil, Gold and Stock Markets. The Energy Journal, 39, 193207.

Corsi, F., Pirino, D., \& Reno, R. (2010). Threshold bipower variation and the impact of jumps on volatility forecasting. Journal of Econometrics, 159(2), 276-288.

Cunado, J., Gupta, R., Lau, C. K. M., \& Sheng, X. (2019). Time-Varying Impact of Geopolitical Risks on Oil Prices. Defence and Peace Economics. DOI: https://doi.org/10.1080/10242694.2018.1563854.

Da, Z., Engelberg, J., \& Gao, P. (2015). The sum of all FEARS investor sentiment and asset prices. The Review of Financial Studies, 28(1), 1-32.

Das, D., Kumar, S. B., Tiwari, A. K., Shahbaz, M., \& Hasim, H. M. (2018). On the relationship of gold, crude oil, stocks with financial stress: A causality-in-quantiles approach. Finance Research Letters, 27, 169-174.

Demirer, R., Gkillas, K., Gupta, R., \& Pierdzioch, C. (Forthcoming). Time-varying Risk Aversion and Realized Gold Volatility. The North American Journal of Economics and Finance, 50, 101048.

Degiannakis, S., \& Filis, G (2017). Forecasting oil price realized volatility using information channels from other asset classes. Journal of International Money and Finance, 76(C), 2849.

Diks, C., \& Panchenko, V. (2005). A note on the Hiemstra-Jones test for Granger noncausality. Studies in nonlinear Dynamics \& Econometrics, 9(2), Article No. 4.

Diks, C., \& Panchenko, V. (2006). A new statistic and practical guidelines for nonparametric Granger causality testing. Journal of Economic Dynamics and Control, 30(9-10), 16471669.

Dufour, J. M., \& Renault, E. (1998). Short run and long run causality in time series: theory. Econometrica, 66(5), 1099-1125.

Dufour, J. M., Pelletier, D., \& Renault, É. (2006). Short run and long run causality in time series: inference. Journal of Econometrics, 132(2), 337-362.

Dunham, L.M., \& Friesen, G.C. (2007). An empirical examination of jump risk in U.S. equity and bond markets. North American Actuarial Journal, 11(4), 76-91.

Ewing, B. T., \& Malik, F. (2013). Volatility transmission between gold and oil futures under structural breaks. International Review of Economics \& Finance, 25, 113-121.

Fattouh, B., Kilian, L., \& Mahadeva, L. (2013). The role of speculation in oil markets: What have we learned so far? The Energy Journal, 34(3), 7-33.

Giot, P., Laurent, S., \& Petitjean, M. (2010). Trading activity, realized volatility and jumps. Journal of Empirical Finance, 17, 168-175.

Gkillas, K., Gupta, R., \& Pierdzioch, C. (Forthcoming). Forecasting realized oil-price volatility: The Role of financial stress and asymmetric loss. Journal of International Money and Finance.

Granger, C.W.J. (1969). Investigating causal relations by econometric models and crossspectral methods. Econometrica, 37(3), 424-438. 
Greenwood-Nimmo, M., Nguyen, V.H., \& Rafferty, B.(2016). Risk and return spillovers among the G10 currencies. Journal of Financial Markets, 31, 43-62.

Gürgün, G., \& Ünalmış, İ. (2014). Is gold a safe haven against equity market investment in emerging and developing countries? Finance Research Letters, 11(4), 341-348.

Harvey, C. R., Liechty, J. C., Liechty, M. W., \& Müller, P. (2010). Portfolio selection with higher moments. Quantitative Finance, 10(5), 469-485.

Hiemstra, C., \& Jones, J. D. (1994). Testing for linear and nonlinear Granger causality in the stock price-volume relation. The Journal of Finance, 49(5), 1639-1664.

Hill, J. B. (2007). Efficient tests of long-run causation in trivariate VAR processes with a rolling window study of the money-income relationship. Journal of Applied Econometrics, 22(4), 747-765.

Horvath, L., Pouliot, W., \& Wang, S. (2017). Detecting at-Most-m Changes in Linear Regression Models. Journal of Time Series Analysis, 38(4), 552-590.

Huang, X., \& Tauchen, G.E. (2005). The Relative Contribution of Jumps to Total Price Variance. Journal of Financial Econometrics, 3(4), 456-499.

Jondeau, E., \& Rockinger, M. (2006). Optimal portfolio allocation under higher moments. European Financial Management, 12(1), 29-55.

Komunjer, I. (2007). Asymmetric power distribution: Theory and applications to risk measurement. Journal of Applied Econometrics, 22(5), 891-921.

Kräussl, R., Lehnert, T., \& Senulyte, S. (2016). Euro crash risk. Journal of Empirical Finance, 38, 417-428.

Kumar, S. (2017). On the nonlinear relation between crude oil and gold. Resources Policy, 51, 219-224.

Lau, C. K. M, Vigne, S. A., Wang, S., \& Yarovaya, L. (2017). Return spillovers between white precious metal ETFs: the role of oil, gold, and global equity. International Review of Financial Analysis, 52, 316-332.

Mensi, W., Beljid, M., Boubaker, A., \& Managi, S. (2013). Correlations and volatility spillovers across commodity and stock markets: Linking energies, food, and gold. Economic Modelling, 32, 15-22.

Mwamba, J. W. M., Hammoudeh, S., \& Gupta, R. (2017). Financial tail risks in conventional and Islamic stock markets: a comparative analysis. Pacific-Basin Finance Journal, 42, 6082.

Nolte, I., \& Xu, Q. (2015). The Economic Value of Volatility Timing with Realized Jumps. Journal of Empirical Finance, 34, 45-59.

Pierdzioch, C., \& Gupta, R. (2019). Uncertainty and Forecasts of U.S. Recessions. Studies in Nonlinear Dynamics and Econometrics. DOI: https://doi.org/10.1515/snde-2018-0083.

Plakandaras, V., Cunado, J., Gupta, R., \& Wohar, M. E. (2017). Do leading indicators forecast U.S. recessions? A nonlinear re-evaluation using historical data. International Finance, 20(3), 289-316.

Reboredo, J. C. (2013a). Is gold a safe haven or a hedge for the US dollar? Implications for risk management. Journal of Banking \& Finance, 37(8), 2665-2676.

Reboredo, J. C. (2013b). Is gold a hedge or safe haven against oil price movements? Resources Policy, 38(2), 130-137.

Salamaliki, P. K., \& Venetis, I. A. (2013). Energy consumption and real GDP in G-7: Multihorizon causality testing in the presence of capital stock. Energy economics, 39, 108-121.

Shrestha, K. (2014). Price discovery in energy markets. Energy Economics, 45, 229-233.

Silvennoinen, A., \& Thorp, S. (2013). Financialization, crisis and commodity correlation dynamics. Journal of International Financial Markets, Institutions and Money, 24, 42-65.

Stock, J. H. \& Watson, M. W. (2003). Forecasting output and inflation: the role of asset prices. Journal of Economic Literature, 41, 788-829. 
Tang, K., \& Xiong, W. (2012). Index investment and the financialization of commodities. Financial Analysts Journal, 68(6), 54-74.

Tiwari, A.K., Aye, G.C., Gupta, R., \& Gkillas, K. (Forthcoming). Gold-Oil Dependence Dynamics and the Role of Geopolitical Risks: Evidence from a Markov-Switching TimeVarying Copula Model. Energy Economics.

Yaya, O. S., Tumala, M. M., \& Udomboso, C. G. (2016). Volatility persistence and returns spillovers between oil and gold prices: Analysis before and after the global financial crisis. Resources Policy, 49, 273-281.

Zhou, H., \& Zhu, J. Q. (2012). An empirical examination of jump risk in asset pricing and volatility forecasting in China's equity and bond markets. Pacific-Basin Finance Journal, 20(5), 857-880. 


\section{Appendix A. Technical Details}

\section{A.1. Nonlinear Causality Test}

We briefly summarize the test statistics of Diks and Panchenko (2006) and its asymptotic properties. Under the null hypothesis of Granger non-causality

$$
H_{0}: X_{t} \text { does not Granger cause } Y_{t}
$$

Denote $Z_{t}=Y_{t+1}$ and $W_{t}=\left(X_{t}, Y_{t}, Z_{t}\right)$. The distribution of $W_{t}$ is invariant under $H_{0}$ and thus it is convenient to drop the time subscripts and make the notation more compact as $W=(X, Y, Z)$. Based on the idea of conditional independence under the null, the joint probability density function $f_{X, Y, Z}(x, y, z)$ and its marginals must follow

$$
\frac{f_{X, Y, Z}(x, y, z)}{f_{Y}(y)}=\frac{f_{X, Y}(x, y)}{f_{Y}(y)} \frac{f_{Y, Z}(y, z)}{f_{Y}(y)}
$$

where $(x, y, z)$ are the fixed values of $(X, Y, Z)$. DP firstly show that equation (15) implies

$$
q_{g} \equiv \mathbb{E}\left[\left(\frac{f_{X, Y, Z}(x, y, z)}{f_{Y}(y)}-\frac{f_{X, Y}(x, y)}{f_{Y}(y)} \frac{f_{Y, Z}(y, z)}{f_{Y}(y)}\right) g(X, Y, Z)\right]=0
$$

By choosing a symmetric weighting function $g(X, Y, Z)=f_{Y}^{2}(y)$, Equation (16) is simplified as

$$
q=\mathbb{E}\left[f_{X, Y, Z}(x, y, z) f_{Y}(y)-f_{X, Y}(x, y) f_{Y, Z}(y, z)\right]=0
$$

At this point, it is necessary to have local density estimators of a $d_{w}$-variate random vector $W$ at $W_{i}$.

Denote the local density estimators as

$$
\hat{f}_{W}\left(W_{i}\right)=\frac{(2 \varepsilon)^{-d_{W}}}{n-1} \sum_{j, j \neq i} \mathbb{I}\left(\left\|W_{i}-W_{j}\right\|<\varepsilon\right)
$$

where $\mathbb{I}(\cdot)$ is the indicator function and $\varepsilon$ is the bandwidth. Diks and Panchenko (2006) further propose an estimator $T_{n}$ for $q$.

$$
T_{n}(\varepsilon)=\frac{n-1}{n(n-2)} \sum_{i}\left(\hat{f}_{X, Y, Z}\left(X_{i}, Y_{i}, Z_{i}\right) \hat{f}_{Y}\left(Y_{i}\right)-\hat{f}_{X, Y}\left(X_{i}, Y_{i}\right) \hat{f}_{Y, Z}\left(Y_{i}, Z_{i}\right)\right)
$$


With the choice of the bandwidth depending on the sample size, $\varepsilon_{n}=C n^{-\beta}, C>0$ and $\beta \in$ $(1 / 4,1 / 3)$, Diks and Panchenko (2006) derives the asympototics for $T_{n}\left(\varepsilon_{n}\right)$ as

$$
\sqrt{n} \frac{\left(T_{n}\left(\varepsilon_{n}\right)-q\right)}{S_{n}} \stackrel{d}{\rightarrow} N(0,1)
$$

where $S_{n}$ is the estimated standard error of $T_{n}\left(\varepsilon_{n}\right)$. For the optimal choice of the bandwidth $\varepsilon_{n}$, an interested reader can refer to the discussion in Diks and Panchenko (2006).

\section{A.2. Hill (2007) Causality Test}

Given a trivariate VAR of order $p$ with zero constants

$$
V_{t}=\sum_{i=1}^{p} \pi_{i} V_{t-i}+\varepsilon_{t}
$$

where $V_{t}=\left(X_{t}, Y_{t}, U_{t}\right)^{\prime}, \mathrm{U}_{\mathrm{t}}$ is the auxiliary variable, $\pi_{i}$ is the coefficients matrix with dimension

$3 \times 3$. Then it is easy to use recursion to show an $h$-step-ahead linear forecast of $V_{t+h}$, give the information set $I_{V}(t)$.

$$
\widehat{V}_{t+h}\left|I_{V}(t)=\sum_{i=1}^{p} \pi_{i} \widehat{V}_{t+h-i}\right| I_{V}(t)=\sum_{i=1}^{p} \pi_{i}^{(h)} \widehat{V}_{t+1-i}
$$

where the $h$-step-ahead coefficients matrix $\left\{\pi_{i}^{(h)}\right\}_{i=1}^{p}$ satisfying the nonlinear recursion

$$
\pi_{1}^{(0)}=I_{m}, \quad \pi_{j}^{(1)}=\pi_{j}, \quad \pi_{j}^{(h)}=\pi_{j+1}^{(h-1)}+\pi_{1}^{(h-1)} \pi_{j}
$$

Then coefficients matrix $\pi_{i}^{(h)}$ can be expressed as

$$
\pi_{j}^{(h)}=\left[\begin{array}{lll}
\pi_{X X, j}^{(h)} & \pi_{X Y, j}^{(h)} & \pi_{X U, j}^{(h)} \\
\pi_{Y X, j}^{(h)} & \pi_{Y Y, j}^{(h)} & \pi_{Y U, j}^{(h)} \\
\pi_{U X, j}^{(h)} & \pi_{U Y, j}^{(h)} & \pi_{U U, j}^{(h)}
\end{array}\right]
$$

Given Equation (24), Dufour and Renault (1998) shows how to use Wald statistics to formulate the noncausality test.

$$
Y_{t} \stackrel{h}{\rightarrow} X_{t} \mid I_{X U} \text { if and only } \pi_{X Y, j}^{(h)}=0, \forall j=1,2, \ldots p
$$


The sequential test procedure is consisted by three steps. Step 1 is to test whether $Y$ ever causes $X$ at all horizon $h>0$.

$$
\begin{aligned}
& H_{0}^{(\infty)}: Y \stackrel{1}{\rightarrow}(X, U) \\
& H_{0}^{(\infty)}:(Y, U) \stackrel{1}{\rightarrow} X
\end{aligned}
$$

According to Hill (2007, Theorem 2.1), if $Y \stackrel{1}{\rightarrow}(X, U) \mid I_{X U}$ or $(Y, U) \stackrel{1}{\rightarrow} X \mid I_{X Z}$, then $Y \stackrel{(\infty)}{\rightarrow} X \mid I_{X Z}$. Fail to reject either Test 0.1 or Test 0.2 implies the detection of non-causality at all horizons. Rejection in both Test 0.1 and 0.2 leads to proceed with the horizon-specific non-causality test in the following two steps. Step 2 is to initially test whether $Y$ does not cause $X$ one-step-ahead (Test 1.0).

$$
H_{0}^{(1.0)}: Y \stackrel{1}{\nrightarrow} X
$$

Rejection of Test 1.0 suggests a direct causality from $\mathrm{Y}$ to $\mathrm{X}$ at horizon one. If fail to reject Test 1.0, then proceed to investigate the existence of a causal chain by the two tests below.

$$
\begin{aligned}
& H_{0}^{(1.1)}: Y \stackrel{1}{\rightarrow} U \\
& H_{0}^{(1.2)}: U \stackrel{1}{\rightarrow} X
\end{aligned}
$$

If fail to reject either Test 1.1 or 1.2, there is a broken causal chain and it can be concluded that $Y$ never causes $X$. Conversely, the rejection of both Test 1.1 and 1.2 indicates the presentence of a causal chain and proceed with Step 3 which aims to test non-causality up to horizon $h \geq 2$.

$$
H_{0}^{(h .0)}: Y \stackrel{(h)}{\rightarrow} X
$$

The asymptotic distribution of the Wald-type statistics follows $\chi^{2}$, which is a poor proxy under the finite small samples and the standard Wald tests in multivariate models tend to over-reject the null hypothesis (Dufour et al., 2006). Thus, Hill (2007) applied a parametric bootstrap method to obtain the $p$-values of the test, which can provide reasonable approximations to the chosen significance levels. It is important to highlight that Hill (2007) test procedure is subject to the multiple testing problem. To 
tackle such problem, it is necessary to correct the overall size of the test by using Bonferroni-type test size bound, which is elaborated in Hill (2007, p756). In addition, Hill (2007) applied the test procedure based on a rolling-window to reveal the evolution in the long-run causality.

\section{A.3. Causality in Moments Test}

Chen (2016) developed a generalized parametric approach to test Granger causality in various moments and establish a class of cross-causality tests for Granger causality in mean, variance, quantile, and crosscausality for a pair of returns series $\left\{y_{i t}\right\}, i=1,2$ and $t=1, \ldots, T$. Chen's (2016) test is applicable for the full-sample and out-of-sample contexts. Here we briefly summarize the test in the full-sample context.

Denote $\mathfrak{V}_{i, t-1}$ as the information set generated by the $y_{i, t-k}$ for all $k>0$ and $\mathfrak{V}_{t-1} \equiv\left(\mathfrak{V}_{1, t-1}, \mathfrak{V}_{2, t-1}\right)$. The null hypothesis that $y_{2 t}$ does not Granger cause $y_{1 t}$ in various moments can be formulated as

$$
\mathbb{E}\left(\phi\left(y_{1 t}\right) \mid \mathfrak{Y}_{t-1}\right)=\mathbb{E}\left(\phi\left(y_{1 t}\right) \mid \mathfrak{Y}_{1, t-1}\right)
$$

Some special cases ${ }^{17}$ with the specification for the moment function $\phi(\cdot)$ are as follows.

- No causality in mean:

$$
\mathbb{E}\left(\phi_{1}\left(y_{1 t}\right) \mid \mathfrak{Y}_{t-1}\right)=\mathbb{E}\left(\phi_{1}\left(y_{1 t}\right) \mid \mathfrak{Y}_{1, t-1}\right) \text {, where } \phi_{1}\left(y_{1 t}\right) \equiv y_{1 t}
$$

- No causality in variance:

$$
\mathbb{E}\left(\phi_{2}\left(y_{1 t}\right) \mid \mathfrak{Y}_{t-1}\right)=\mathbb{E}\left(\phi_{2}\left(y_{1 t}\right) \mid \mathfrak{Y}_{1, t-1}\right) \text {, where } \phi_{2}\left(y_{1 t}\right) \equiv y_{1 t}^{2}
$$

- No causality in quantiles:

$$
\begin{gathered}
\mathbb{E}\left(\phi_{q}\left(y_{1 t}\right) \mid \mathfrak{Y}_{t-1}\right)=\mathbb{E}\left(\phi_{q}\left(y_{1 t}\right) \mid \mathfrak{Y}_{1, t-1}\right), \\
\text { where } \phi_{q}\left(y_{1 t}\right) \equiv \mathbb{I}\left(Q_{i t}\left(\tau_{1}\right)<y_{1 t} \leq Q_{i t}\left(\tau_{2}\right)\right)
\end{gathered}
$$

and $Q_{i t}(\tau)$ is the $\tau$-quantile of $F_{i}\left(\cdot \mid \mathfrak{V}_{1, t-1}\right)$ with $\tau \in[0,1]$

\footnotetext{
${ }^{17}$ The cross-causality tests can be defined in a similar way, such as no causality from quantiles to mean/variance and vice versa.
} 
The test is based on the standardized residuals $\left\{\varepsilon_{i t}\right\}, i=1,2$ from a GARCH-type model with parameter $\theta$ for the raw return. In a similar way, define the moment functions $\varphi(\cdot)$ for the standardized residuals, $\varepsilon_{i t}$.

$$
\begin{gathered}
\varphi_{i t}^{(1)} \equiv \varepsilon_{i t} \\
\varphi_{i \mathrm{t}}^{(2)} \equiv \varepsilon_{i t}^{2}-1 \\
\varphi_{i \mathrm{t}}^{(q)} \equiv \mathbb{I}\left(Q_{\varepsilon, i t}\left(\tau_{1} \mid \beta_{i}\right)<\varepsilon_{i t} \leq Q_{\varepsilon, i t}\left(\tau_{2} \mid \beta_{i}\right)-\left(\tau_{2}-\tau_{1}\right)\right)
\end{gathered}
$$

Define $\varphi_{i t} \equiv \varphi_{i t}\left(\theta_{i}\right)$ as $\varphi_{i t}^{(1)}, \varphi_{i \mathrm{t}}^{(2)}, \varphi_{i \mathrm{t}}^{(q)}$ or any other zero-mean transformation of $\varepsilon_{i t}$, where $\theta_{i}$ is parameter vector (containing $\beta_{i}$ ) of the conditional model for $y_{i t} \mid \mathfrak{Y}_{i, t-1}$. In order to estimate the sample cross-causality, it is necessary to introduce some more notations, $\varphi_{i, o t} \equiv \varphi\left(\theta_{i o}\right), \varphi_{i, o t}^{c} \equiv \varphi_{i, o t}-$ $\mathbb{E}\left[\varphi\left(\theta_{i o}\right)\right], \sigma_{i}^{2} \equiv \mathbb{E}\left[\left(\varphi_{i, o t}^{c}\right)^{2}\right], \hat{\varphi}_{i t} \equiv \varphi_{i t}\left(\hat{\theta}_{i t}\right), \quad \bar{\varphi}_{l} \equiv T^{-1} \sum_{t=1}^{T} \hat{\varphi}_{i t}, \quad \hat{\varphi}_{i t}^{c} \equiv \hat{\varphi}_{i t}-\bar{\varphi}_{l}$ and $\quad \bar{\sigma}_{i}^{2} \equiv$ $T^{-1} \sum_{t=1}^{T}\left(\hat{\varphi}_{i t}^{c}\right)^{2}$. Then the generalized cross-causality at lag $k$ is defined as $\rho_{k} \equiv \operatorname{corr}\left(\varphi_{1, o t}, \varphi_{2, o t-k}\right)$ and its finite sample version can be estimated by

$$
\hat{\rho}_{k} \equiv \frac{1}{T} \sum_{t=1}^{T}\left(\frac{\hat{\varphi}_{1 t}^{c}}{\bar{\sigma}_{1}}\right)\left(\frac{\hat{\varphi}_{2, t-k}^{c}}{\bar{\sigma}_{2}}\right)
$$

Denote $\hat{\rho} \equiv\left(\hat{\rho}_{1}, \hat{\rho}_{2}, \ldots, \hat{\rho}_{n}\right)$ and $\hat{\mathcal{v}} \equiv\left(\bar{\sigma}_{1} \bar{\sigma}_{2}\right) \times I_{n}$, where $n$ is a finite integer that $n \ll T$. Finally, the null hypothesis is tested by the proposed $G_{\rho}$ statistics with its asymptotic distribution.

$$
G_{\rho} \equiv T(\mathcal{S} \hat{\rho})^{\top}\left(\mathcal{S} \hat{\mathcal{V}}^{-1} \widehat{\Omega} \hat{\mathcal{V}}^{-1} \mathcal{S}^{\top}\right)^{-1}(\mathcal{S} \hat{\rho}) \stackrel{d}{\rightarrow} \chi^{2}(q)
$$

where $\mathcal{S}$ is a weighting matrix with dimension $q \times n$ and $\widehat{\Omega}$ is the variance covariance matrix. 


\section{Appendix B. Additional Results}

Table B1. Summary Statistics

\begin{tabular}{|c|c|c|c|c|c|c|c|c|c|c|}
\hline \multirow[b]{2}{*}{ Statistic } & \multicolumn{5}{|c|}{ Gold } & \multicolumn{5}{|c|}{ Oil } \\
\hline & $r$ & $R V$ & $\boldsymbol{R J}$ & RSK & $R K U$ & $r$ & $R V$ & $\boldsymbol{R J}$ & RSK & $R K U$ \\
\hline Mean & 0.0002 & 0.0001 & 0 & -0.0073 & 9.8412 & 0.0002 & 0.0004 & 0 & -0.0373 & 9.7147 \\
\hline Median & 0.0003 & 0.0001 & 0 & -0.0155 & 6.5458 & 0.0003 & 0.0003 & 0 & -0.0368 & 6.8049 \\
\hline Maximum & 0.0959 & 0.0044 & 0.0006 & 10.1096 & 382.7679 & 0.1722 & 0.005 & 0.0015 & 9.9328 & 244.7567 \\
\hline Minimum & -0.0858 & 0 & 0 & -10.2952 & 1.6671 & -0.1654 & 0 & 0 & -13.0038 & 1.5 \\
\hline Std. Dev. & 0.0102 & 0.0002 & 0 & 1.2173 & 12.9393 & 0.0214 & 0.0005 & 0 & 1.1781 & 12.2363 \\
\hline Kurtosis & 10.1319 & 139.1781 & 509.4392 & 16.6456 & 168.6773 & 7.3764 & 19.6604 & 361.0132 & 18.519 & 103.2092 \\
\hline Jarque-Bera & 12225.15 & 4529114 & 61912395 & 44779.78 & 6675373 & 4625.901 & 77960.62 & 30925903 & 57838.82 & 2474895 \\
\hline$p$-value & 0 & 0 & 0 & 0 & 0 & 0 & 0 & 0 & 0 & 0 \\
\hline$N$ & & & & & & & & & & \\
\hline
\end{tabular}

Note: $r$ : returns; $R V$ : realized volatility; $R J$ : jumps; $R S K$ : realized skewness, and; $R K U$ : realized kurtosis; Std. Dev: standard deviation; $p$-value corresponds to the Jarque-Bera test with the null of normality. 
Table B2. BDS Test of Nonlinearity

\begin{tabular}{|c|c|c|c|c|c|}
\hline \multirow{2}{*}{$\begin{array}{l}\text { Dependent } \\
\text { Variable }\end{array}$} & \multicolumn{5}{|c|}{ Dimension } \\
\hline & 2 & 3 & 4 & 5 & 6 \\
\hline$r$ : Gold & $9.981 * * *$ & $11.579 * * *$ & $12.868 * * *$ & $13.839 * * *$ & $15.089 * * *$ \\
\hline$r:$ Oil & $9.542 * * *$ & $13.104 * * *$ & $15.091^{* * *}$ & $17.094^{* * *}$ & $19.133 * * *$ \\
\hline$R V:$ Gold & $31.797 * * *$ & $36.482 * * *$ & $39.539 * * *$ & $42.785^{* * *}$ & $46.546^{* * *}$ \\
\hline$R V:$ Oil & $34.438 * * *$ & $40.788^{* * *}$ & $45.583^{* * *}$ & $50.127 * * *$ & $55.656 * * *$ \\
\hline RJ: Gold & $27.647 * * *$ & $34.423 * * *$ & $39.837^{* * *}$ & $44.983^{* * *}$ & $50.502 * * *$ \\
\hline RJ: Oil & $30.026 * * *$ & $36.812^{* * *}$ & $42.462 * * *$ & $48.072 * * *$ & $54.154 * * *$ \\
\hline RSK: Gold & $6.457 * * *$ & $9.869 * * *$ & $13.726 * * *$ & $16.668 * * *$ & $19.598 * * *$ \\
\hline RSK: Oil & $8.652 * * *$ & $11.863 * * *$ & $15.214^{* * *}$ & $17.659 * * *$ & $19.947 * * *$ \\
\hline RKU: Gold & $7.965 * * *$ & $9.687 * * *$ & $12.336 * * *$ & $14.484 * * *$ & $16.116^{* * *}$ \\
\hline RKU: Oil & $5.291 * * *$ & $6.687 * * *$ & $7.461 * * *$ & $8.019 * * *$ & $8.725^{* * *}$ \\
\hline
\end{tabular}

Note: See Notes to Table B1; The test is performed on the residuals of the individual equation of the $\operatorname{VAR}(p)$ model used for the linear Granger causality test; *** indicates the rejection of the null of i.i.d. residuals at the $1 \%$ level of significance, with the entries in the Table being Brock et al.,'s (1996) z-statistic. 
Table B3. Bai and Perron (2003) Test of Multiple Structural Breaks

\begin{tabular}{|c|c|}
\hline Dependent Variable & Dates \\
\hline r: Gold & No Breaks \\
\hline$r:$ Oil & No Breaks \\
\hline$R V:$ Gold & 2/7/2002; 1/16/2006; 10/29/2008; 9/29/2011 \\
\hline$R V:$ Oil & 1/16/2002; 3/12/2006; 1/9/2009; 8/18/2014 \\
\hline RJ: Gold & $6 / 4 / 2001 ; 12 / 3 / 2006$ \\
\hline RJ: Oil & 6/11/2001; 5/21/2006 \\
\hline RSK: Gold & 08/07/2013 \\
\hline RSK: Oil & $3 / 16 / 2014$ \\
\hline RKU: Gold & 2/23/2009; 2/21/2012 \\
\hline RKU: Oil & $11 / 22 / 2006$ \\
\hline
\end{tabular}


Table B4. Test Statistics of the Change-Point Test of Horvath et al. (2017)

\begin{tabular}{lcc}
\hline & Dependent Variable: Oil & Dependent Variable: Gold \\
\hline $\boldsymbol{r}$ & 2.350 & 1.830 \\
$\boldsymbol{R} \boldsymbol{R}$ & 1.421 & 2.250 \\
$\boldsymbol{R} \boldsymbol{N}$ & $26.614^{* * *}$ & $18.230^{* * *}$ \\
$\boldsymbol{R S K}$ & $11.166^{* * *}$ & $4.741^{* *}$ \\
$\boldsymbol{R} \boldsymbol{K} \boldsymbol{N}$ & $29.099^{* * *}$ & $16.489^{* * *}$
\end{tabular}

Note: See Notes to Table B1; The test is applied on each equation of the $\operatorname{VAR}(p)$ model used for the linear Granger causality test; Critical values are 3.54 at $10 \% ; 4.46$ at $5 \%$; and 6.43 at $1 \%$; ${ }^{* * *}$ indicates rejection of the null of no-change at $1 \%$ level of significance. 
Table B5. $p$-Values of Casualty-in-Moments Test over an Out-of-Sample Period of January 2, 2012May 26, 2017

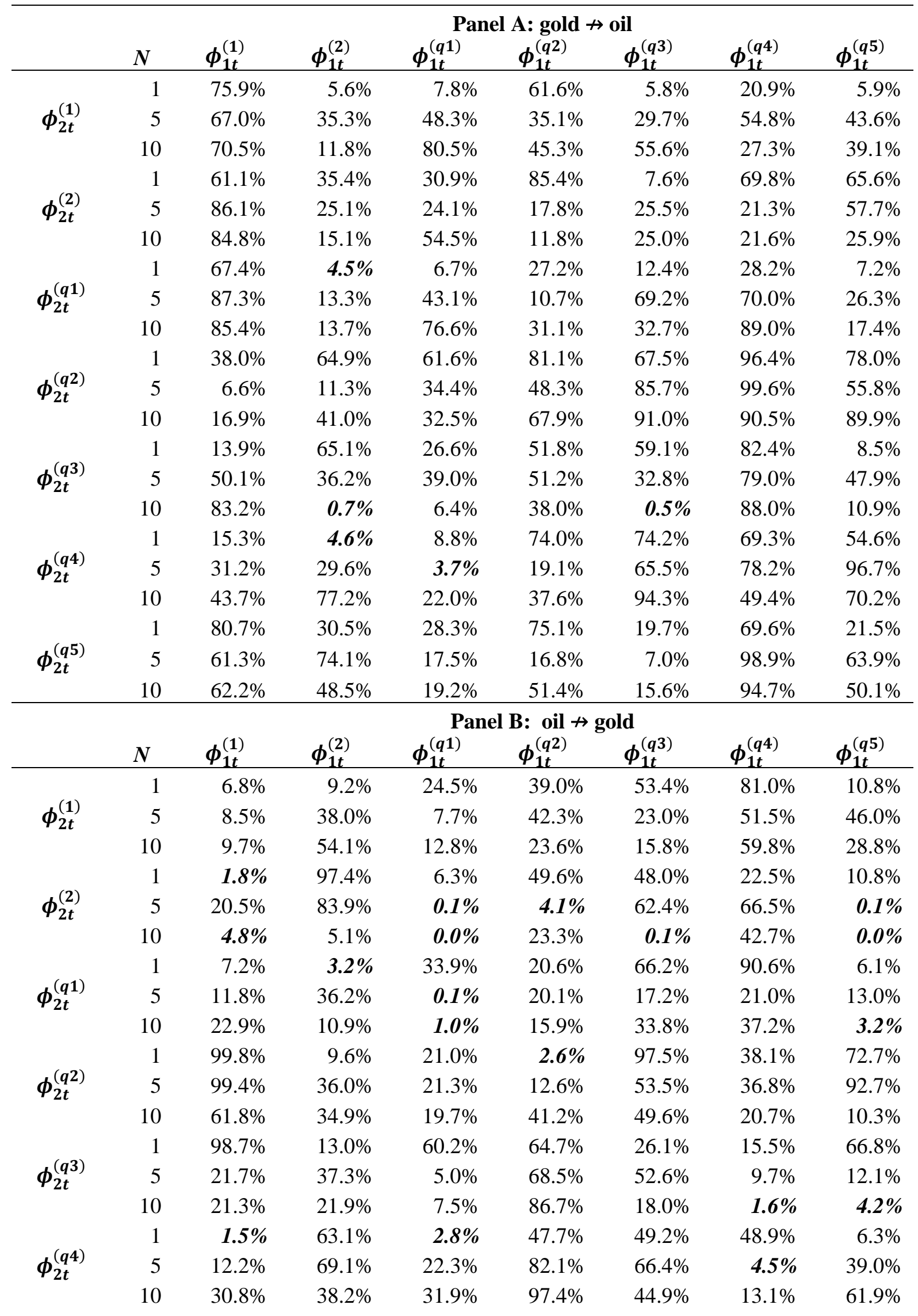




\begin{tabular}{rrrrrrrrr} 
& 1 & $63.5 \%$ & $19.6 \%$ & $43.9 \%$ & $99.3 \%$ & $96.7 \%$ & $88.4 \%$ & $55.2 \%$ \\
$\boldsymbol{\phi}_{2 \boldsymbol{t}}^{(\boldsymbol{q} 5)}$ & 5 & $73.2 \%$ & $\mathbf{1 . 4 \%}$ & $81.2 \%$ & $80.8 \%$ & $50.0 \%$ & $3.9 \%$ & $21.6 \%$ \\
& 10 & $32.4 \%$ & $\mathbf{4 . 4 \%}$ & $8.0 \%$ & $82.4 \%$ & $3.7 \%$ & $6.1 \%$ & $32.6 \%$ \\
\hline
\end{tabular}

Note: $\phi_{i t}^{(1)}$ is the first moment, $\phi_{i t}^{(2)}$ is the second moment, $\phi_{i t}^{(q 1)}$ is the quantile of $(0,0.2), \phi_{i t}^{(q 2)}$ is the quantile of $(0.2,0.4), \phi_{i t}^{(q 3)}$ is the quantile of $(0.4,0.6), \phi_{i t}^{(q 4)}$ is the quantile of $(0.6,0.8)$, and $\phi_{i t}^{(q 5)}$ is the quantile of $(0.8,1)$. 

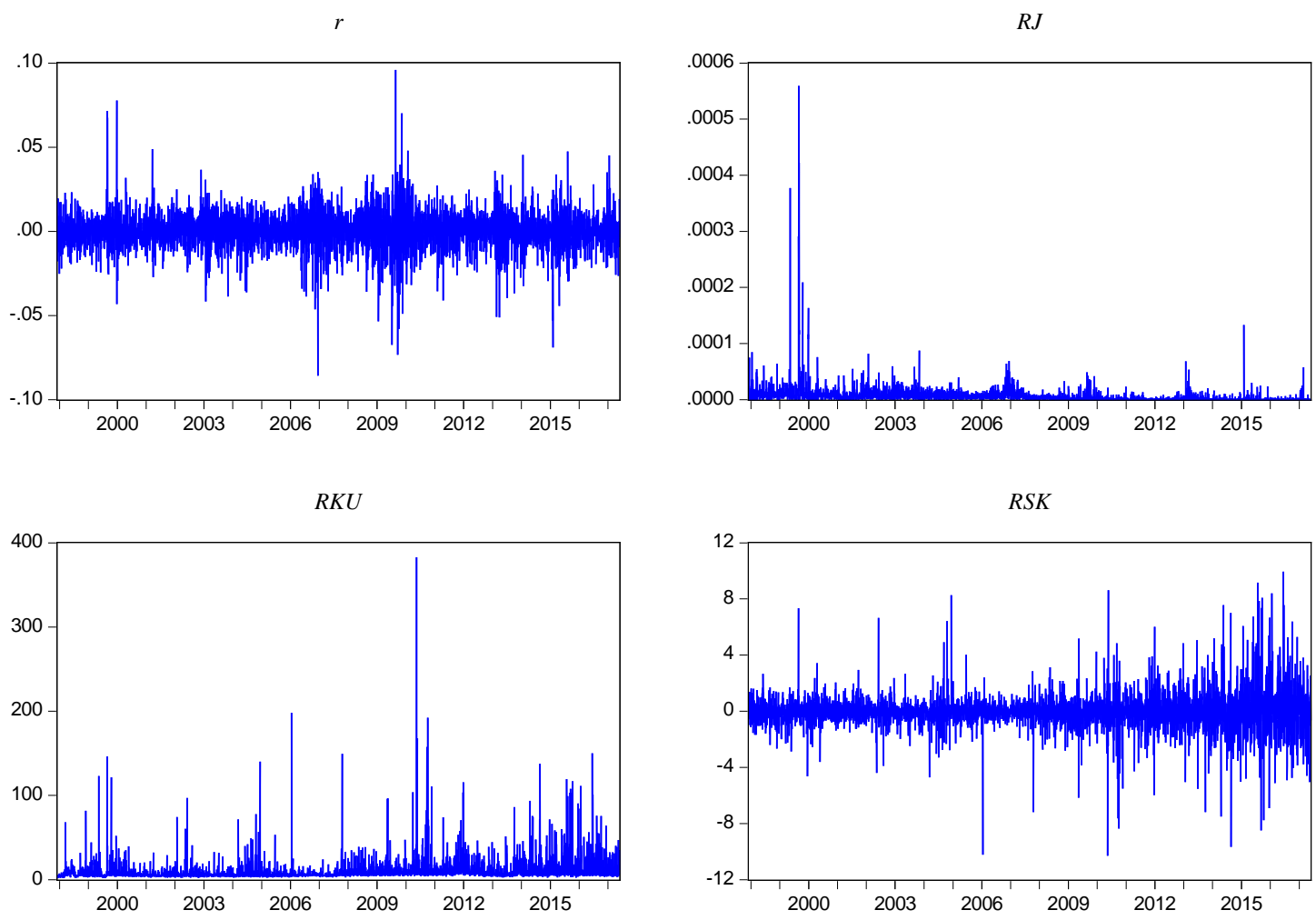

$R V$

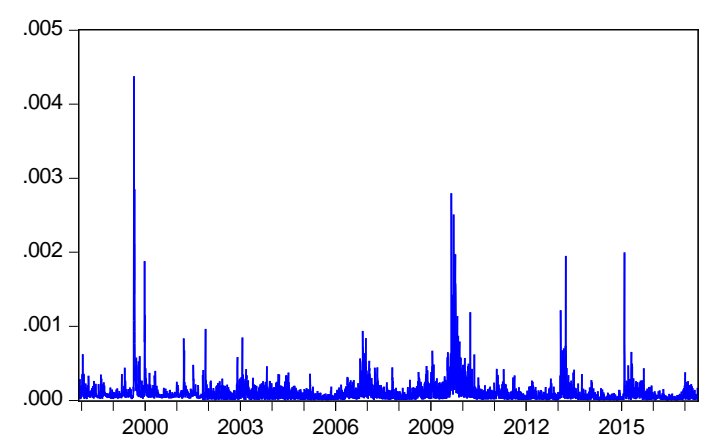

Figure B1 (a). Data Plots of Gold Market

Note: $r$ : returns; $R V$ : realized volatility; $R J$ : jumps; $R S K$ : realized skewness, and; $R K U$ : realized kurtosis. 
$r$

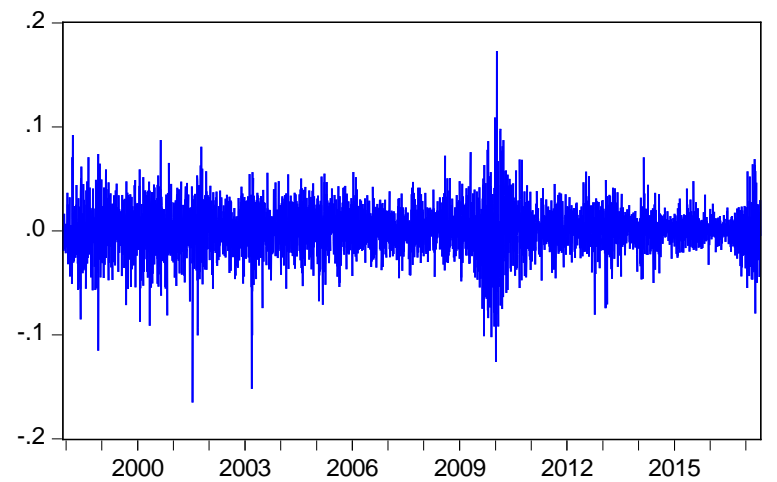

$R K U$

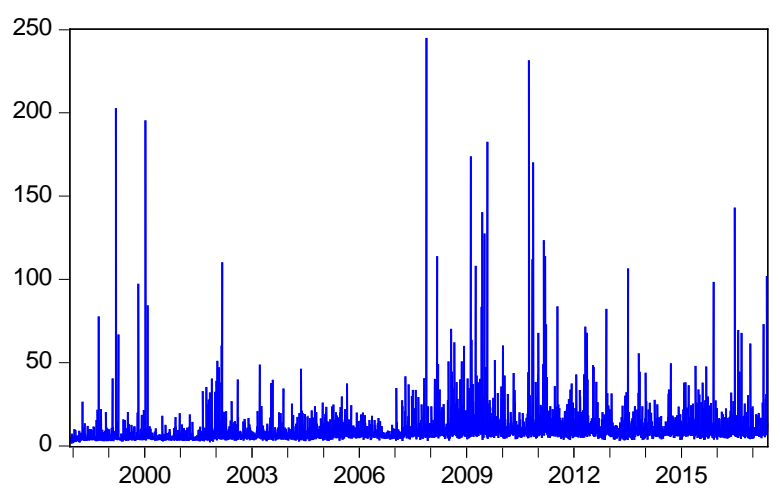

$R V$

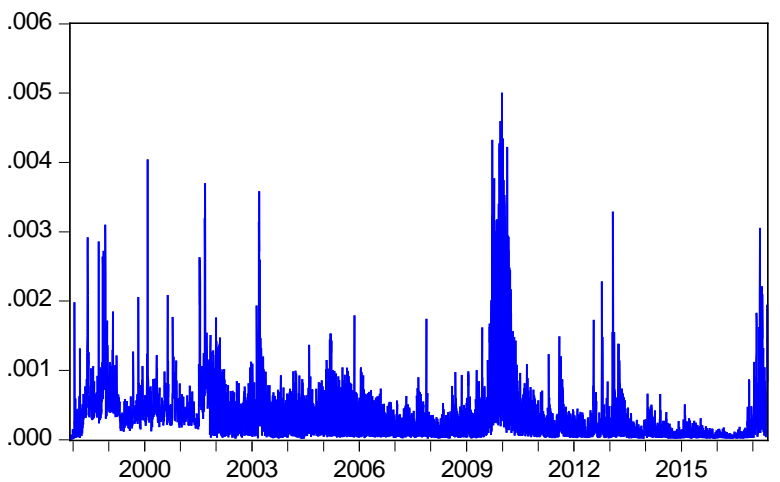

$R J$

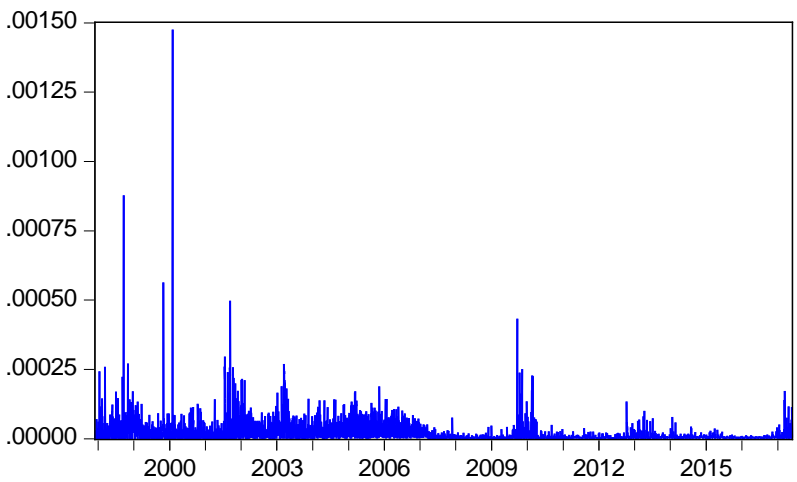

RSK

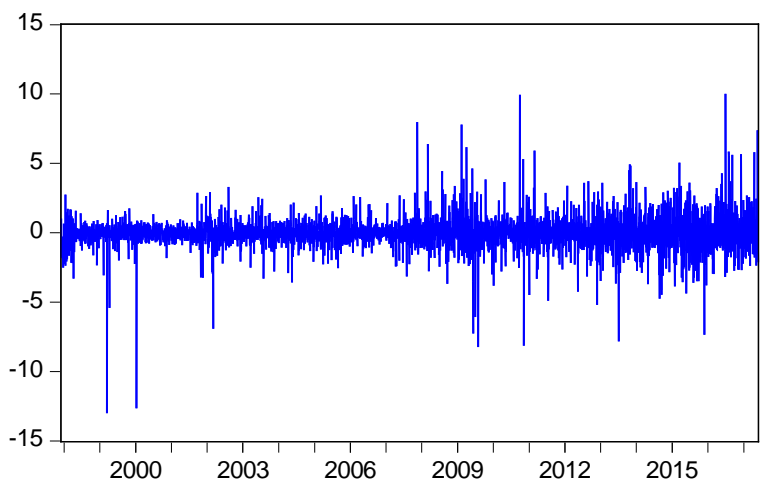

Figure B1 (b). Data Plots of Oil Market

Note: $r$ : returns; $R V$ : realized volatility; $R J$ : jumps; $R S K$ : realized skewness, and; $R K U$ : realized kurtosis. 